5

\title{
Multi-wavelength speciation of high-temperature 1-butene pyrolysis
}

\author{
Nicolas H. Pinkowski*, Séan J. Cassady, David F. Davidson, Ronald K. Hanson \\ High Temperature Gasdynamics Laboratory, Department of Mechanical Engineering, Stanford \\ University, Stanford, CA 94305-3032, USA
}

\section{Abstract}

Species time-history measurements provide important kinetics targets for the development and validation of detailed reaction models. Here, a multi-wavelength, multi-species laser absorption strategy is demonstrated that provides high-bandwidth species time-histories during 1-butene pyrolysis behind reflected shock waves. Measured shock tube absorbance traces at nine wavelengths were used to resolve nine species mole fractions in the pyrolysis of 5\% 1-butene in argon at $1300 \mathrm{~K}, 1.8 \mathrm{~atm}$. In addition to existing sensors for 1-butene, methane, ethylene, 1,3-butadiene, propene, allene, benzene, and cyclopentadiene, a new laser absorption sensor for ethane at $3.3519 \mu \mathrm{m}$ was developed by measuring cross-sections of ethane and of expected major interferers. Additional measurements to complete a square absorption cross-section matrix were also performed that enabled the simultaneous solution of species mole fractions from absorbance time-histories under appropriate physical system constraints. Measured time-histories of the nine product species were also compared with existing flow-reactorbased kinetic mechanisms. The demonstrated method has further application potential in the speciation of larger, more complex fuels.

Keywords:1-butene, hydrocarbon pyrolysis, high temperature, time-resolved, laser absorption spectroscopy, cross-sections, ethane diagnostic, shock tubes

\section{Introduction}

\footnotetext{
* Corresponding Author

Email address: npinkows@stanford.edu
} 
In recent years, efforts to improve detailed kinetic models have motivated the development of

27 advancedspeciation techniques inhigh-temperature studies of hydrocarbon fuels[1].In particular,

28 therecently introduced hybrid chemistry modeling approach known as HyChem relies on accurate

29 species time-history measurements during the thermal decomposition of hydrocarbons [2-5]. At the

30 shorttimescales needed to resolve such fast pyrolysis chemistry, shock tube facilitiescan provide a wide

31 range of well-controlled experimental conditions, and laser absorption spectroscopy offers a high-

32 bandwidth measurement technique for resolving the formation and removal of individual species[6,7].

33 Historically, laser absorption at $3.392 \mu \mathrm{m}$ has been a popular choice for measuring time-histories of fuels

34 in shock tube kinetics research[8-11]. However, the measured absorbance at any single wavelength may

35 result from the composite absorption of a blend of species with overlapping spectral features, a

36 phenomenon that can obfuscate the determination of individual time-histories in real-fuel

37 experiments.To circumvent this challenge, carefullyselected diagnostic wavelengths have been

38 developed to enable targeted measurements of individual species such as methane [12,13], ethylene [14-

39 16], acetylene[17], and iso-butene[18]. In cases where discrete, narrow features are measured, the two-

40 color online/offline technique described in [13]can be used to subtract spectral interference from larger

41 absorbers.

42 However, for species with broader features, such a technique is not always possible. Instead, multi-

43 wavelength diagnostic techniques have been developed for resolving multiple species simultaneously.

44 For example, Parise et al. [19]present a two-wavelength, two-species diagnostic measuring ethylene and

45 propene, and a three-wavelength version that includes iso-butene[20]. In such multi-wavelength

46 speciation methods, measured species serve as unknowns in the simultaneous solution of a system of

47 equations (wavelengths). In fact, the online/offline technique can be thought of as a special case of

48 multi-wavelength speciation: under the assumption of flat interfering absorbance, the online and offline

49 wavelengths provide two equations for two unknowns (absorbance from the target species, and that of all

50 other interferers). Recently, Pinkowski et al. [21]have extended this technique to any number of species 
51 within a convex optimization framework. They compiled adatabase of cross-sections for eleven species

52 at eleven sensitive wavelengths, many of which have been used for standalone diagnostics in the works

53 cited above. The present study represents the first demonstration of this method with application to the

54 pyrolysis of the smallest alkene with an isomeric structure: 1-butene. However, literature data on 1-

55 butene pyrolysis in a flow reactor [22] predicts the formation of a measurable amount of ethane, for

56 which this speciation effort must account. Consequently, the goals of the present work are (1) to provide

57 species time-histories at representative conditions during the high-temperature pyrolysis of 1-butene, (2)

58 to develop a new wavelength for sensitive measurements of ethane in a shock tube, (3) to supplement the

59 cross-section matrix of [21]with species and wavelengths relevant to 1-butene pyrolysis, and (4)

60 demonstratethe convex speciation method described in[21].

61

\section{2. Background}

63

\subsection{Laser absorption spectroscopy}

65

66 Laser absorption spectroscopy leveragesthe propensity of matter to absorb lightto enablequantitative 67 measurements of species gas properties.Shown in Eq. 1,the Beer-Lambert equation relates the 68 attenuation ofmonochromatic light at wavelength $\lambda$ to the number density of a species. Absorbance $(\alpha)$

69 is defined as the negative natural logarithm of the transmission $\left(I / I_{0}\right)$. The absorbance is related to the 70 product of the number density of the $i^{\text {th }}$ species $\left(n_{i}\right)$ and measurement path length $(L)$ through a 71 proportionality factor $(\sigma)$ known as absorption cross-section. The absorption cross-section is a 72 wavelength-, temperature-, pressure-, and composition-dependent property of a species that describes its 73 interaction with light. 


$$
\left.\alpha_{\lambda}=-\ln \frac{I}{I_{0}}\right)=n_{i} \sigma_{\lambda} L
$$

75

$$
\begin{gathered}
\sigma_{C H 4, \lambda_{1}} x_{C H 4}+\sigma_{C 2 H 4, \lambda_{1}} x_{C 2 H 4}+\cdots \sigma_{N, \lambda_{1}} x_{i}=\frac{\alpha_{\lambda_{1}}}{n L} \\
\sigma_{C H 4, \lambda_{2}} x_{C H 4}+\sigma_{C 2 H 4, \lambda_{2}} x_{C 2 H 4}+\cdots \sigma_{N, \lambda_{2}} x_{i}=\frac{\alpha_{\lambda_{2}}}{n L} \\
\vdots \\
\sigma_{C H 4, \lambda_{M}} x_{C H 4}+\sigma_{C 2 H 4, \lambda_{M}} x_{C 2 H 4}+\cdots \sigma_{N, \lambda_{M}} x_{i}=\frac{\alpha_{\lambda_{M}}}{n L}
\end{gathered}
$$
vector $\left\{\vec{b} \in \mathbb{R}^{\mathrm{M}} \mid \vec{b}=\vec{\alpha} / n L\right\}\left(\mathrm{m}^{2} \mathrm{~mol}^{-1}\right)$ are established and minimized under constraints.Eq. 3 presents

Eq. 1 presents a formulation of the Beer-Lambert relation that assumes the presence of only a single absorbing species at a given wavelength. However, when multiple species are present, the absorption spectrum of each canexhibit appreciable overlap.Therefore, the absorbance $\alpha_{\lambda}$ at wavelength $\lambda$ becomesthecomposite absorbancecontributed by all constituents. Isolating and studying one species among a variegated blend presents a challenge for kinetics studies. To supportthe determination of mole fractions from blended absorbance measurements, a variety of simultaneouslyprobedwavelengths can be used to discern between the unique spectral shapes of each individual absorber. In principle, if $N$ absorbing species are present, at least $N$ wavelengthsof light are needed to create a system of linear equations that can be solved for the mole fraction of all species. Eq. 2 presents representation of thevectorized formulation of the Beer-Lambert relation for $N$ species and $M$ wavelengths, with $x$ denoting mole fraction.

A convex speciation framework has been proposed by Pinkowski et al.[21] to enable the simultaneous calculation of mole fractions from a blended set of absorbance measurements. A crosssection matrix $\left\{\mathrm{K} \in \mathbb{R}^{\mathrm{M} \times \mathrm{N}}\right\} \quad\left(\mathrm{m}^{2} \mathrm{~mol}^{-1}\right)$, mole fraction vector $\left\{\vec{x} \in \mathbb{R}^{\mathrm{N}}\right\}$, and normalized absorbance the objective function and constraints used in the current study.Eq. 3 is solved for a vector of mole 
94 fractions using CVX software from CVX Research Inc. [23,24]. Because temperature, and consequently 95 number density, were not well-known in the present study, the system was solved using the absorption 96 coefficient matrix $k\left(\mathrm{~atm}^{-1} \mathrm{~cm}^{-1}\right)$ and pressure-normalized vector $\vec{b}=\vec{\alpha} / P L\left(\mathrm{~atm}^{-1} \mathrm{~cm}^{-1}\right)$ instead of their 97 cross-sectional counterparts (defined in terms of $\mathrm{m}^{2} \mathrm{~mol}^{-1}$ ). Both methods are equivalent; the latter 98 simply uses more readilymeasured quantities in its solution.

99

\author{
Minimize $\|k \vec{x}-\vec{b}\|_{2}^{2}$ \\ Subject to: \\ 1) $\vec{x} \geq 0$ \\ 2) The calculated number of hydrogen and \\ carbon atoms must not exceed the known \\ amount at time-zero \\ 3) $k \vec{x} \leq \vec{b}$
}

Three constraints are used in the solution of $\vec{x}$ : (1) that the mole fractions must be positive, (2) that the calculated number of atoms must not exceed the known number of atoms at time-zero, and (3) that the sum of the absorbance contribution from each species must be less than or equal to the measured absorbance at each wavelength. The first and second constraints enforce physicallyvalid mole fractions and the third constraint asserts that no combination of species can absorb more than measured. The third constraintcreates a system thatis robust to interfering absorbersbyimposing onlypositive or zero unaccounted absorbance of magnitude $(\vec{b}-k \vec{x})\left(\operatorname{atm}^{-1} \mathrm{~cm}^{-1}\right)$ 

used in the current study to facilitate measurements of cross-sections and species time-histories. The two

112 shock tubes consist of 2.8 meter- and 3.35 meter-longhigh-pressure driver gas regions, respectively, and

$1139.5 / 8.54$ meter-long regions for low-pressure driven gas. Polycarbonate diaphragms between $0.125 \mathrm{~mm}$

114 and $0.25 \mathrm{~mm}$ were used to separateeach regionand were designed to burst with a pressure differential

115 between 1 and 3 atm. Each shock tube uses a reflected shock wave to nearlyinstantaneously generate a

116 well-controlled region of high temperature and pressure near the endwall of the driven section. The

117 initial temperature, pressure, and composition of the test gas, along with measurements of the incident 118 shock velocity from five pressure transducerslocated along the length of the driven section, are all used 119 to determine the thermodynamic state of the gas at time-zero, when the reflected shock passes the 120 measurement plane. In the present work, a shock condition calculator developed by Campbell et al. 121 [25]was used to calculate these conditions. The calculator uses the shock jump equations along with assumptions of frozen chemistry anda vibrationallyrelaxedsystemafter the incident and reflected shock.Supporting the validity of both assumptions, good agreement wasobserved between measured and calculated pressures in the present study. Additional support is found in the literature in similar shock tube work[26].

\subsection{Laser systems} through one of the two shock tubes to capture absorption time-histories across a range of conditions.

131 Each shock tube had six optical ports offering three lines-of-sight through which one or two lasers were 132 simultaneously aligned. In total, three separate optical configurations were constructed between both 133 shock tubes to enable measurements of all conditions with all lasers. Experimental tests were duplicated 134 with at least one common laser in each successive configuration to ensure consistent absorption 135 measurements throughout the entire experimental domain. Lasers were chosen with output wavelengths 
strongly sensitive to methane (tunable interband cascade laser (ICL), online/offline: $3.1758 \mu \mathrm{m} / 3.17595$ $\mu \mathrm{m}[12]$ ), aromatics (ICL, $3.283 \mu \mathrm{m}$ [21]), ethane (ICL, $3.3519 \mu \mathrm{m}$, new in this work), ethylene $\left(\mathrm{CO}_{2}\right.$ gas

138

a)

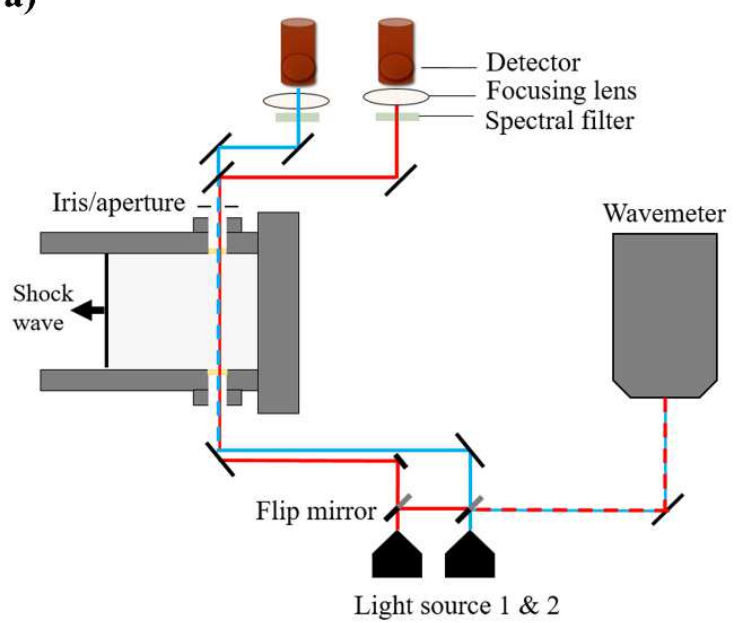

b)

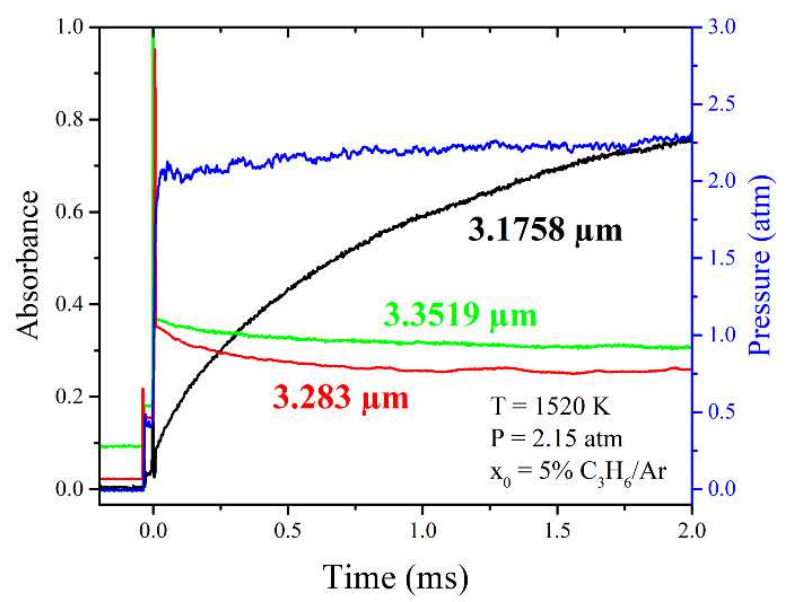

Fig. 1. (a) Experimental setup of two lasers aligned through one window of a shock tube. (b) Example absorbance and pressure measurements from a shock tube experiment of $5 \%$ propene $\left(\mathrm{C}_{3} \mathrm{H}_{6}\right)$ in $\operatorname{argon}$ and an initial temperature of $1520 \mathrm{~K}$. 
Fig.1(a) shows a representative two-dimensional schematic of a shock tube facility instrumented with laser diagnostics for kinetics studies. Laser light traverses the test section of the tube through two optical ports and is focused onto individual detectors. Laser measurements near $3 \mu \mathrm{m}$ generally use sapphire window ports, while systems with laser light near $10 \mu \mathrm{m}$ use zinc selenide windows. In the present study, all optical setups included narrow-bandpass spectral filters to mitigate detection of thermal emission from the high-temperature gases. Focusing optics were used immediately before either liquid nitrogen-cooled photovoltaic indium antimonide detectors for 3-4 $\mu \mathrm{m}$ light or thermoelectricallycooled photovoltaic mercury cadmium telluride detectors for 10-12 $\mu \mathrm{m}$ light. Example absorption data for the pyrolysis of propene behind a reflected shock wave are shown in Fig. 1(b). Three lasers probing discrete wavelengths in the $3 \mu \mathrm{m}$ region gather information about species formation and removal. Absorbance at $1643.1758 \mu \mathrm{m}$, shown in black in Fig.1(a), is largely attributed to the formation of methane. The two other 165 wavelengths indicated in Fig. 1(a), of $3.3519 \mu \mathrm{m}$ (green) and $3.283 \mu \mathrm{m}$ (red), measure absorption from a variety of different $\mathrm{C}-\mathrm{H}$ vibrational stretch modes with competing intensities.

\subsection{1-butene pyrolysis}

There is a continuing interestin improvingreaction mechanisms for the pyrolysis and oxidation

171 kinetics of butanols, large alkanes (such as n-heptane and iso-octane), and practical fuels such as Jet A.

172 For each of thesefuels, 1-butene is known to be an important intermediate species and pyrolysis product,

173 but despite 1-butene's importance in such mechanisms, only a limited number of studies of high-

174 temperature 1-butene kineticsexist. In the last decade, flow reactor experiments performed byShoaibi et

175 al. [29], Zhang et al. [30], and Wang et al. [22] have guidedthe development of butene176 specificreactionmechanisms.Wang et al. [22] and others[31,32]indicate that fuel fragments from 177 pyrolysis have a strong effect in determining oxidation kinetics.Therefore, characteristics of ignition 178 chemistry can be better understood through an improved understanding of pyrolysis processes. 
Time-resolved speciation is needed for further refinement of the rate constants that dominate $1-\mathrm{C}_{4} \mathrm{H}_{8}$ reaction pathways. Although flow reactors can provide sensitive speciation measurements, limited temporal resolution has inhibitedtheir application to high-temperature chemistry. Single pulse shock tube speciation studies have also been conducted, relying on post-reaction samples to determine pyrolysis yields [33]; however, these frozen samples provide limited insight into early-time reaction pathways. To the authors' knowledge, no laser absorption spectroscopy speciation studies of 1-butene pyrolysis have been conducted, likely due to the heavilyblended spectra of the hydrocarbon products. The recent establishment of a high-temperature spectroscopic cross-section database and a convex speciation

187 framework have enabled the separation of individual species from blended absorption measurements.

188 Data from the literature[22,29,30,33-36] predict the dominant products of 1-butene pyrolysis to be 189 methane $\left(\mathrm{CH}_{4}\right)$, ethylene $\left(\mathrm{C}_{2} \mathrm{H}_{4}\right)$, propene $\left(\mathrm{C}_{3} \mathrm{H}_{6}\right)$, 1,3-butadiene $\left(1,3-\mathrm{C}_{4} \mathrm{H}_{6}\right)$, ethane $\left(\mathrm{C}_{2} \mathrm{H}_{6}\right)$, allene $190\left(\mathrm{aC}_{3} \mathrm{H}_{4}\right)$, benzene $\left(\mathrm{C}_{6} \mathrm{H}_{6}\right)$, and cyclopentadiene $\left(\mathrm{C}_{5} \mathrm{H}_{6}\right)$. To enable the detection of these predicted major 191 species, a new wavelength was included to leverage strong absorption by ethane in the $3-4 \mu \mathrm{m}$ region, and cross-sections of all nine species were measured, determined from the literature, or estimated at each wavelength used.

\section{Multi-wavelength cross-section matrix}

Multi-wavelength speciation methods rely on a collection of high-temperature absorption crosssection measurements at each probed wavelength for all species of interest.In the current study, a ninespecies, nine-wavelength absorption cross-section matrix was used to account for the cross-sections of $\mathrm{CH}_{4}, \mathrm{C}_{2} \mathrm{H}_{4}, \mathrm{C}_{2} \mathrm{H}_{6}, \mathrm{C}_{3} \mathrm{H}_{6}, \mathrm{aC}_{3} \mathrm{H}_{4}$ (allene), 1- $\mathrm{C}_{4} \mathrm{H}_{8}, \mathrm{C}_{4} \mathrm{H}_{6}$ (1,3-butadiene), $\mathrm{C}_{5} \mathrm{H}_{6}$ (cyclopentadiene), and $\mathrm{C}_{6} \mathrm{H}_{6}$ (benzene) at $3.1758 \mu \mathrm{m}, 3.17595 \mu \mathrm{m}, 3.283 \mu \mathrm{m}, 3.3519 \mu \mathrm{m}, 3.392 \mu \mathrm{m}, 10.532 \mu \mathrm{m}, 10.675 \mu \mathrm{m}, 10.958$ $\mu \mathrm{m}$, and $11.345 \mu \mathrm{m}$. Temperature- and occasionally, pressure-dependent cross-section correlations were 203 required for the 81 cells of the matrix. Appendix B presents the collection of absorption cross204 sectionsused to speciate 1-butene pyrolysis. The quantified uncertainty of each cross-section 
205 measurement is particularly important in facilitating a thorough uncertainty quantification of the 206 resulting mole fraction time-histories. For one species, allene, many cross-section approximations were 207 required. However, the majority of the allene absorption cross-sections are predicted to be near zero. In 208 instances where allene absorbs appreciably, such as at $10.958 \mu \mathrm{m}$ and $11.345 \mu \mathrm{m}$, the absorption cross209 sections were either known from [37] or approximated from lower-temperature FTIR data. Ultimately,

210 perturbing these approximated cross-sections was shown to have negligible impact upon the resulting 211 mole fraction time-histories.

\section{4. Experimental details}

215 Experiments on 1-butene utilized two shock tubes, with temperatures ranging from 940 and $1440 \mathrm{~K}$, pressure from $1.5-2.2 \mathrm{~atm}$, and concentrations varying between 3-5\% 1-butene in a bath gas of argon.Self-consistenttemperature trends were observed for all absorbance measurements. Example absorbance traces for $3.283 \mu \mathrm{m}$ and $10.532 \mu \mathrm{m}$ are presented in Fig. 2(a) and (b), respectively. Test times across both shock tube facilities were $2 \mathrm{~ms}$ consistently. The colored data of Fig. 2 were further steering and diaphragm pieces across the beam path. 

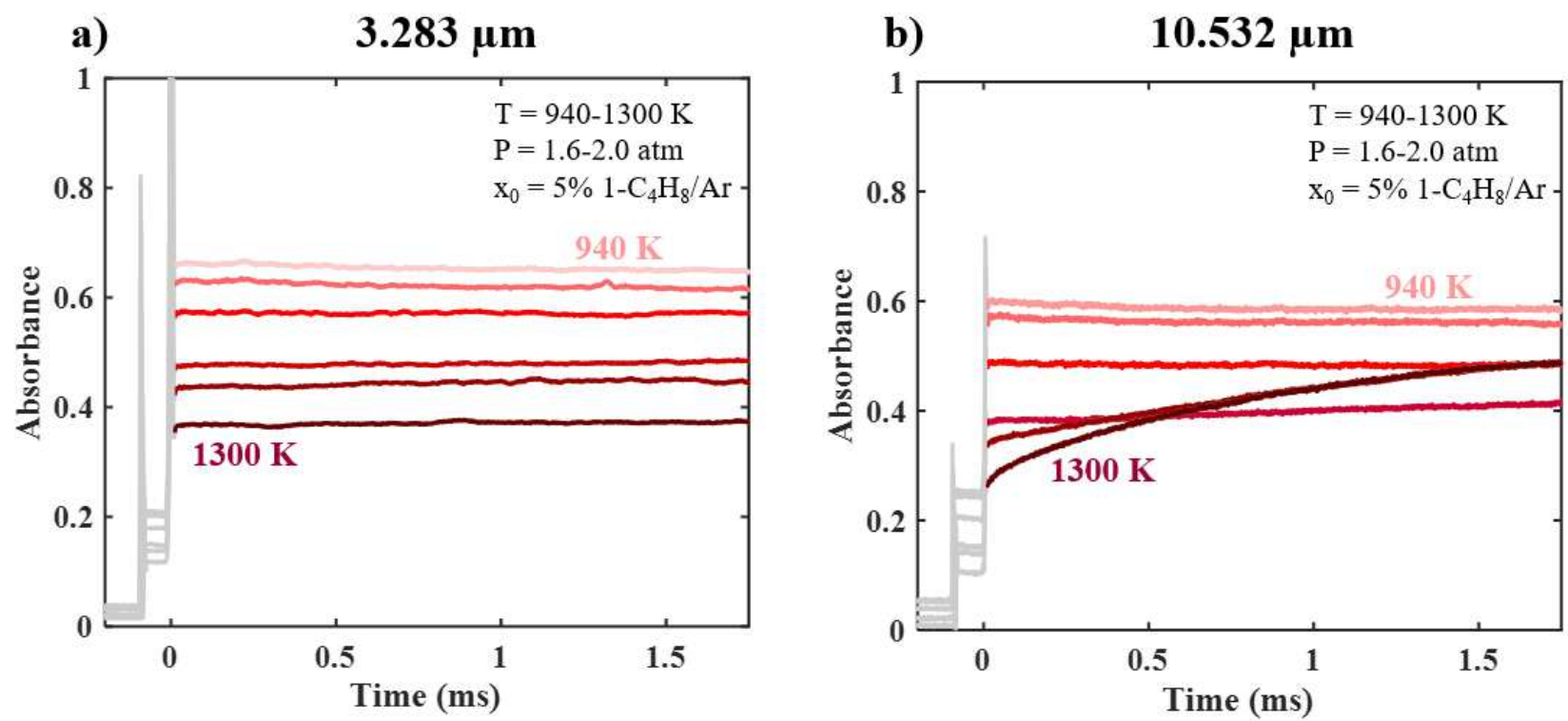

224 Fig. 2. Representative absorbance measurements at (a) $3.283 \mu$ mand (b) $10.532 \mu \mathrm{m}$ of $5 \%$ 1-butene in argon at temperatures of $940 \mathrm{~K}, 946 \mathrm{~K}, 1028 \mathrm{~K}, 1116 \mathrm{~K}, 1220 \mathrm{~K}, 1300 \mathrm{~K}$.

226

Data were collected across a span of temperatures for each wavelength of interest to facilitate the development of cross-section correlations. 1-butene pyrolysis was studied at the commoncondition of $1300 \mathrm{~K}$ and $1.8 \mathrm{~atm}$. To study1-butene pyrolysis at a common condition across all measurements, absorbance data for each wavelength was normalized by pressure and path length and interpolated to produce an approximate absorbance trace at the desired temperature. Uncertainty associated with the interpolation process was mitigated by the use of large number of shock tube measurements very close to $1300 \mathrm{~K}$ and $1.8 \mathrm{~atm}$.

\section{Results and discussion}

\subsection{Laser absorbance traces}


Fig. 3 shows pressure- and path length-normalized absorbance time-histories across the nine selected wavelengths during 5\% 1-butene/Ar pyrolysis at $1300 \mathrm{~K}$ and $1.8 \mathrm{~atm}$. Individual pressure measurements ranged from 1.73-1.85 atm across the experimental domain. For 8 of the 9 wavelengths, the direct output

242 of the interpolated data could be used. However, the absorbance at $10.675 \mu \mathrm{m}$ was fitted to a double

243 exponential due to low-frequency experimental noise introduced by changes in the density (and therefore

244 refractive index) of the sample gas. Data was cropped from the absorbance time-history at $10.958 \mu \mathrm{m}$

245 between 1.5 and $1.75 \mathrm{~ms}$, where the passage of a diaphragm piece created a large deviation in the rise 246 profile.

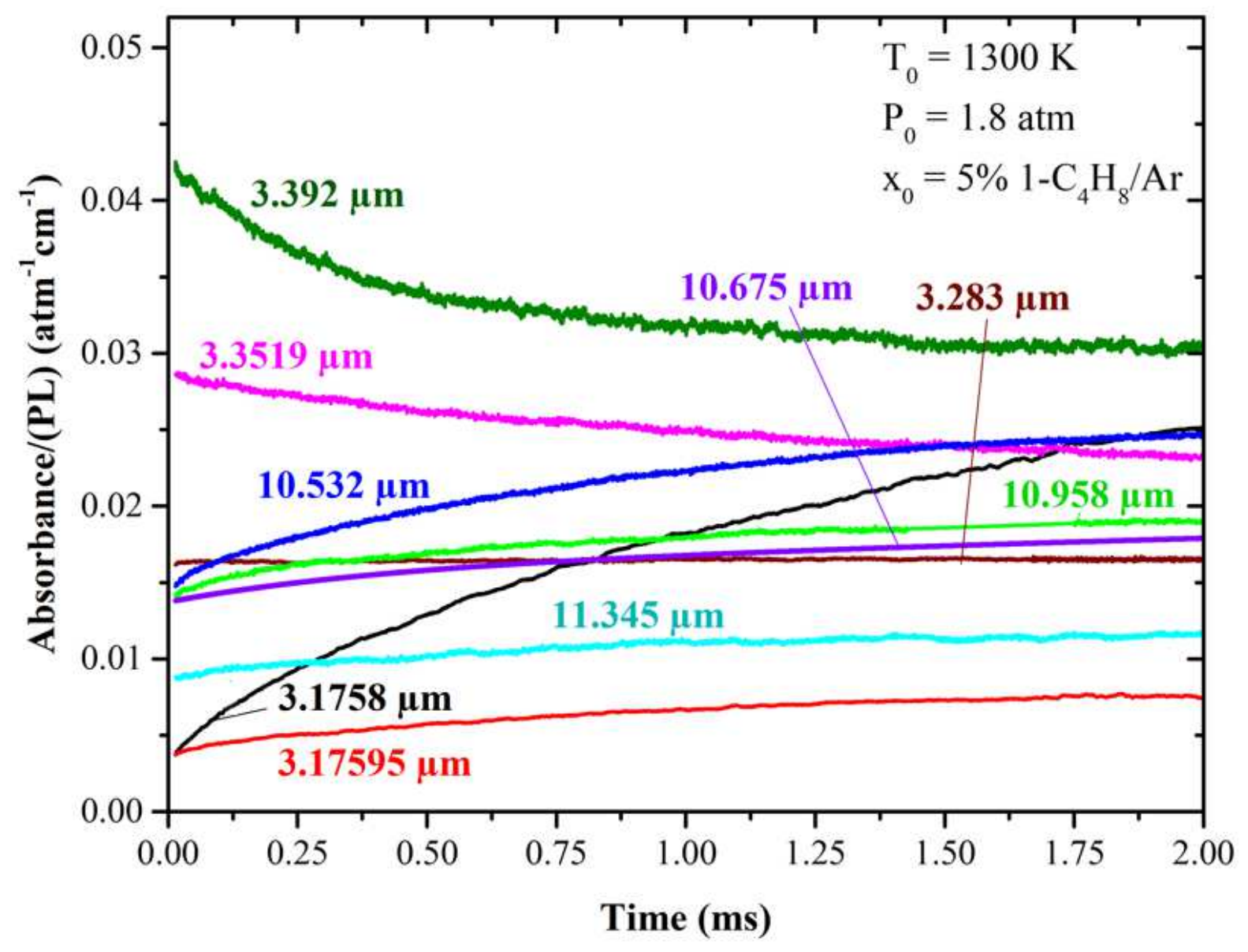

Fig. 3. Pressure- and pathlength-normalized absorbance traces produced at $1300 \mathrm{~K}$ through an interpolation of shock tube measurements near $1300 \mathrm{~K}$. 


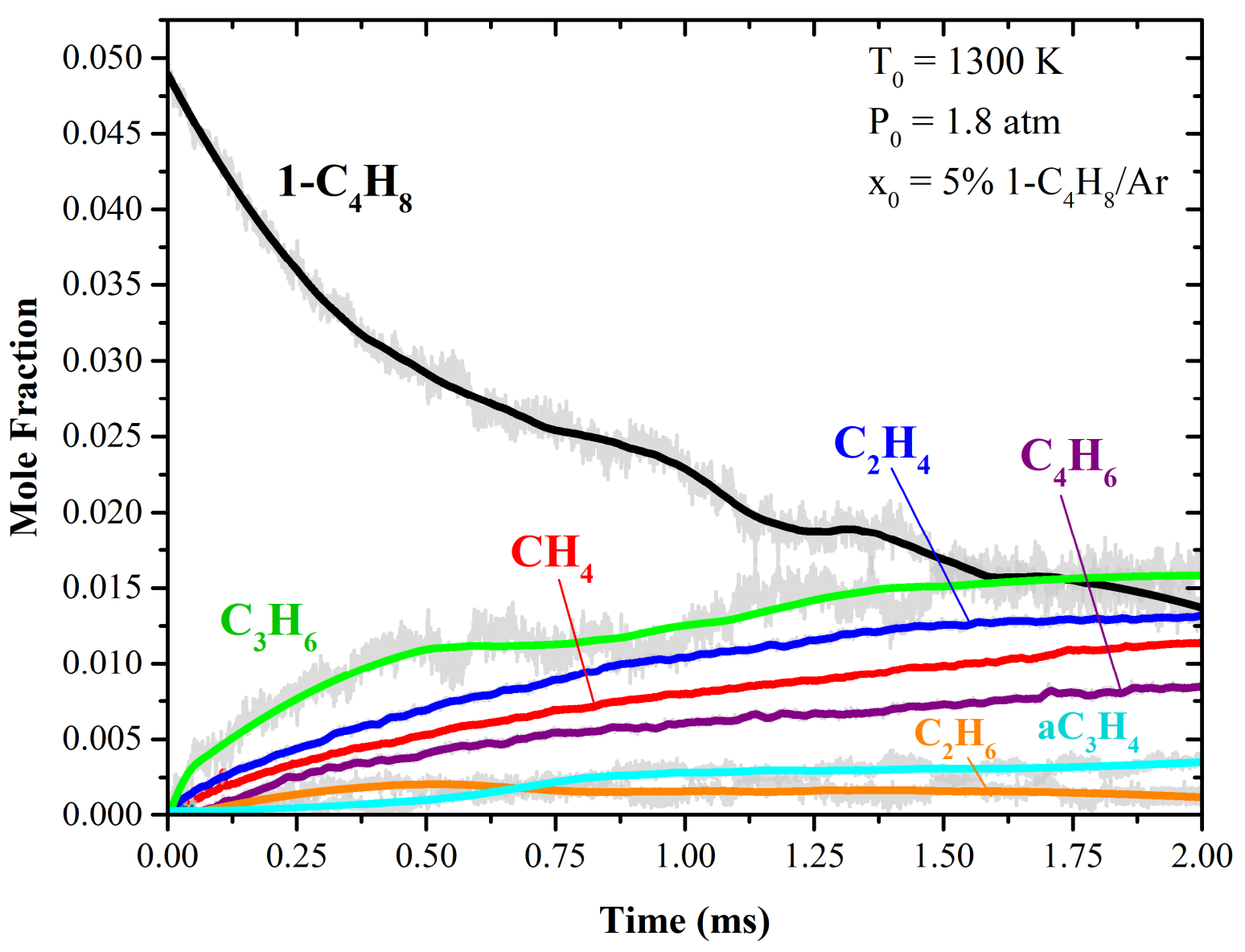

Fig. 4. Inferred mole fractions of $\mathrm{CH}_{4}, \mathrm{C}_{2} \mathrm{H}_{4}, \mathrm{C}_{2} \mathrm{H}_{6}, \mathrm{C}_{3} \mathrm{H}_{6}, \mathrm{aC}_{3} \mathrm{H}_{4}$ (allene), 1- $\mathrm{C}_{4} \mathrm{H}_{8}, \mathrm{C}_{4} \mathrm{H}_{6}$ (1,3-butadiene), pressure and an initial temperature of $1300 \mathrm{~K}$.No appreciable amounts of $\mathrm{C}_{6} \mathrm{H}_{6}$, or $\mathrm{C}_{5} \mathrm{H}_{6}$ weredetected.

Mole fractions werecalculated by applying the convex speciation framework to the absorbance data of Fig. 3 using the database of absorption cross-section correlations presented in [21] and supplemented here. Example results are shown in Fig. 4. At each instant in time, the convex system of absorbance measurements and cross-section correlations was solved using the CVX software through Matlab. The three constraints of Eq. 3were applied to the solution space at all times. The carbon and hydrogen 
264 balance required calculation of the number of the moles in the system,which was estimated from a 265 balance of inert argon using Eq. 4.

$$
\widehat{N}_{t}=\left(\frac{x_{0, A r}}{\hat{x}_{t, A r}}\right) N_{0}
$$

$266 \widehat{N}_{t}$ and $\hat{x}_{t, A r}$ are predictions of the total number of moles and mole fraction of argon at time $t$, and $267 N_{0}, x_{0, A r}$ are the total number of moles and mole fraction of argon at time-zero. The time-dependent 268 mole fraction of argon was estimated using Eq. 5, assuming the majority of species weremeasured. 269

$$
\hat{x}_{t, A r} \approx 1-\sum_{i=1}^{N} x_{i}
$$

Because minor species were discounted when estimating the mole fraction of argon, the calculated total number of moles in the system $\left(\widehat{N}_{t}\right)$ may slightly underestimate the true molar sum $\left(N_{t}\right)$. However, 272 this systematic error serves to under-constrain, rather than artificially over-constrain, the atomic 273 conservation condition. Nevertheless, because all major species were measured, this method is expected 274 to yield accurate estimates.

275 The solution for mole fractions showed a propensity to fill the hydrogen constraint completely and 276 leave nearly $4 \%$ carbon free. Without accounting for hydrogen formation, the optimized solution was 277 found toartificially prefer speciescharacterized by ahigh hydrogen-to-carbon ratio. Because we cannot 278 measure hydrogen spectroscopically in the infrared region, a simulated hydrogen profile was used to 279 account for the hydrogen time-history in the system. The Wang et al. and Zhang et al. kinetic models are 280 in excellent agreement with respect to hydrogen formation. Therefore, to fulfill a physicallyvalid 281 hydrogen balance, hydrogen formation was simulated as the average time-historybetween the two models.The free hydrogen and carbon in the systemwere also constrained with a carbon-to-hydrogen ratio consistent with that of expected minor species. 


\subsubsection{Temperature dependence of the absorption cross-sections}

The temperature dependence of the individual absorption cross-section correlations requiredspecification of the temperature profile during the endothermic pyrolysis process. Commonly, a modeled temperature profile is used in speciation[15,17,19,38,39], and the same approach isused in the current study. Amodeled temperature profilewas produced by averaging thepredictions of the Zhang et

al. [30] and Wang et al. [22]mechanisms, which differ by a maximum of only $5 \mathrm{~K}$ at any time. All kinetic modeling was conducted at constant pressure, which wassupported by experimental to the chosen temperature profile.

\subsection{Weighted objective function} their sum can constitute a substantial total. Candidate interfering species include: 2-butene, propane, propyne, pentene, toluene, and xylenes.Thesespecies created interfering absorbance that increased as a function of timeand affectedeach of the nine wavelengths differently.Due to the wavelength dependency of the interference, the system was found to beunavoidably heteroscedastic (characterized by nonuniform variability), and hencea standard least-squares cost function was deemed inappropriate. As

$$
\text { Minimize }\|W(k \vec{x}-\vec{b})\|_{2}^{2}
$$


The matrix $\left\{W \in \mathbb{R}^{\mathrm{M} \times \mathrm{N}} \mid W_{i j}=0\right.$ if $i \neq j$ and $\left.0 \leq W_{i i} \leq 1 \forall i \in\{1,2, \ldots, M\}\right\}$ was chosen to distribute

308 the squared errorevenly across all wavelengths, despitethe presence of interfering species. Weights were

309 selected based on best approximations of the spectra of minor species. The procedure for setting the

310 maindiagonal of matrix $W$ was: (1)candidate interferers were determined using flow reactor data and

311 existing kinetic mechanisms from the literature, (2) where possible, a composite spectrum of the

312 predicted interfering species was generated using low-temperature FTIR data, (3) the combined spectra

313 were used to create a vector ranging from 0 to 1 that indicated the strength of the interference spectrum

314 at each wavelength, and (4) atime-history was generated that decayed from one to(1 - strength)that

315 followed the system rise-time. The system rise-time was determined from the $10.532 \mu \mathrm{m}$ absorbance

316 trace.At each instant in time, the elements of the main diagonal of matrix $W$ were set using the time-

317 histories of (4) at each associated wavelength. Ultimately, the recovered time-histories of most species

318 proved relatively insensitive to the individual weights applied. Numerical perturbation of the weighting

319 structure factors into the measured uncertainty of each species recovered.

\subsection{Uncertaintyquantification}

absorbance measurements, and temperature. The uncertainty, $u$, of species $i$ at time $t$ was calculated to

325 one standard deviationusing Eq. 7,assuming that uncertainty in the absorption cross-sections, 326 absorbance, and the temperature dominate.

$$
u_{i}(t)=\sqrt{\left.\sum_{j=1}^{M} \sum_{k=1}^{N}\left(\frac{\partial x_{i}}{\partial \sigma_{j, k}}\right)^{2} \delta \sigma_{j, k}^{2}+\sum_{j=1}^{M}\left(\frac{\partial x_{i}}{\partial b_{j}}\right)^{2} \delta b_{j}^{2}+\sum_{j=1}^{M}\left(\frac{\partial x_{i}}{\partial W_{j}}\right)^{2} \delta W_{j}^{2}+\frac{\partial x_{i}}{\partial T}\right)^{2} \delta T^{2}}
$$


$328\left(\frac{\partial x_{i}}{\partial \sigma}\right),\left(\frac{\partial x_{i}}{\partial b}\right),\left(\frac{\partial x_{i}}{\partial W}\right)$, and $\left(\frac{\partial x_{i}}{\partial T}\right)$ are computed numerical derivatives of the mole fraction of species $x_{i}$ 329 with respect to the cross-section correlation $\sigma$, normalized absorbance $b$, weight $W$, and the temperature $330 T . \delta \sigma, \delta b, \delta W$, and $\delta T$ are the associated uncertainties of the cross-sections, normalizedabsorbance, 331 weights, and thetemperature to one standard deviation. The cross-sections uncertaintieswere calculated 332 using the parameters in Table 2 and[21] using the method describedin[21]. $\delta b$ was estimated by 333 propagating uncertainty through the Beer-Lambert relation with contributions from path length, pressure, 334 and intensities $I$ and $I_{0}$. Notably, the uncertainty associated with the attenuated intensity $I$ was found to be 335 the dominant source of uncertainty in the absorbance time-histories. Uncertainty in the weights was 336 taken as $\delta W=0.1$. Uncertainty in temperature is conservatively estimated by $\delta T=20 \mathrm{~K}$, which is four 337 times larger than the largest temperature difference between the two models. The measured mole 338 fractions including their uncertaintiesare presented in Fig. 5 to one standard deviation. 

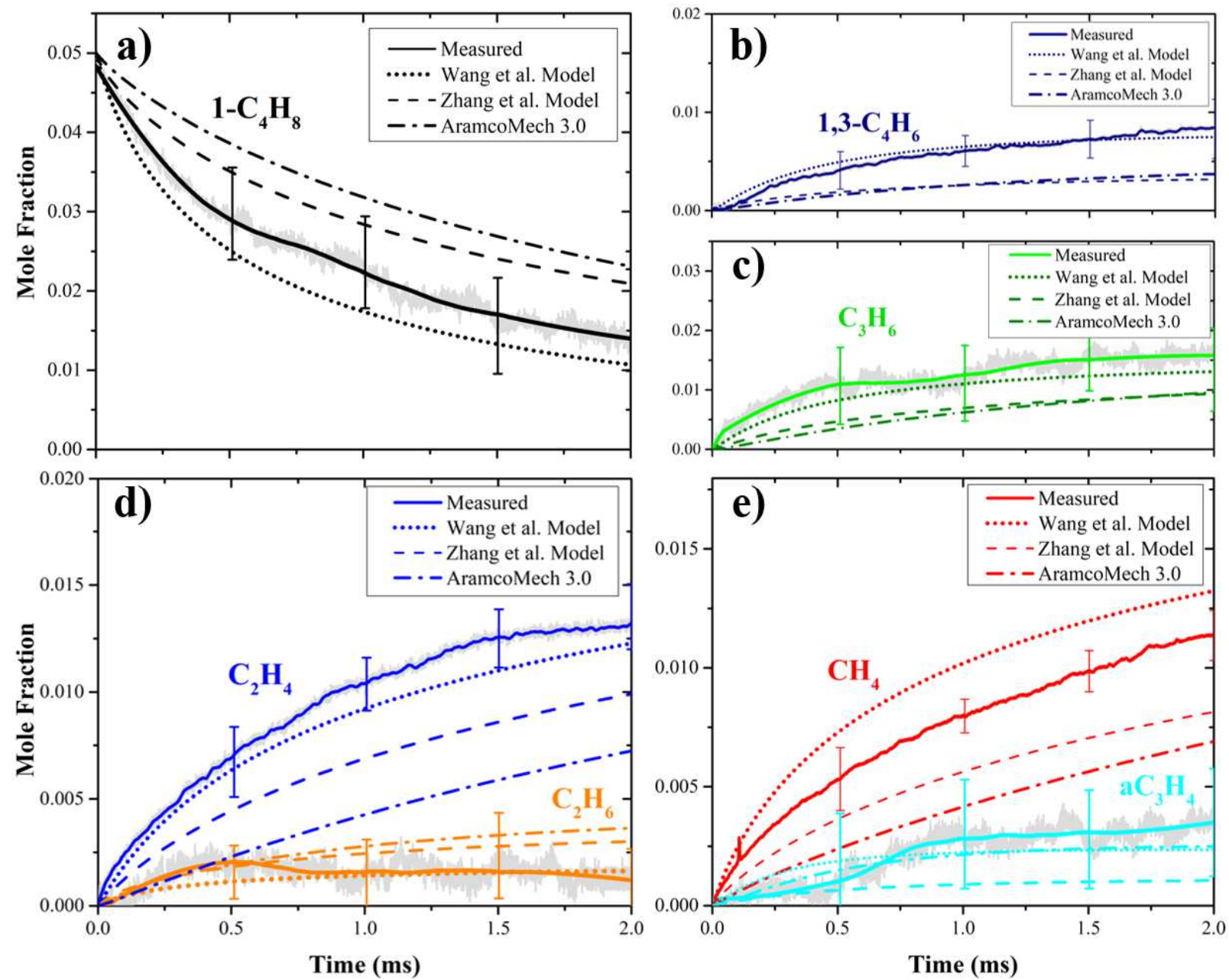

Time (ms)

Time (ms)

341 Fig. 5. Measured mole fractionsversus time in comparison to two 1-butene-specific kinetic models, from

342 Wang et al. [22] and Zhang et al. [30], and also the AramcoMech 3.0 model[40]for (a) 1-butene (b) 1,3-

343 butadiene (c) propene (d) ethylene and ethane, and (e) methane andallene.Error bars represent 1-sigma

344 uncertainty.

The inferred mole fractions and their uncertainties were compared to two 1-butene specific models,

347 the work of Wang et al. [22] and Zhang et al. [30], as well as the Aramco 3.0 kinetic model[40]. Across

348 all species, the measured mole fractions were found to be in good agreement with the predictions of the

349 Wang et al. kinetic model. Two species, 1-butene and methane, were exceptions. They were observed to

350 react at a slower rate than Wang et al. but a faster rate than the Zhang et al. model. For the majority of 
351 species, such as ethylene, 1,3-butadiene, propene, ethane, and allene, the predictions of Wang et al. were 352 well within the experimental uncertainties of the measurements. Comparisons were also drawn 353 againstthe AramcoMech 3.0 kinetic modeland are shown in Fig. 5. A difference in 1-butene 354 decomposition rate was observed between the measured and AramcoMech 3.0 predictions. 355 Consequently,the formation rate of major speciessuch as ethylene, propene, methane, and 1,3-butadiene 356 are predicted to be slower than experimentally measured. Strong agreement exists between AramcoMech $357 \quad 3.0$ and the inferred mole fraction of allene.

358 Within the sensitivity of the current method, only trace amounts of benzene and cyclopentadiene 359 were detected. However, through the uncertainty analysis, valuable insights can be garnered about 360 cylcopentadiene and benzene in comparison to the existing kinetic models, as shown in Fig. 6 (a-b).

361 Concerning cyclopentadiene, the uncertainty bounds for the current method indicate agreement between 362 the inferred mole fractions and the predictions of Wang et al. and AramcoMech 3.0; however, no such 363 agreement exists in comparison to the Zhang et al. mechanism. No appreciable amount of benzene was 364 detected in the current method, yet the measurement uncertainty encompasses the small amounts of 365 benzene predicted from all models. More fixed-wavelength lasers could be added in order to increase 366 measurement sensitivity and decrease uncertainty for trace species.
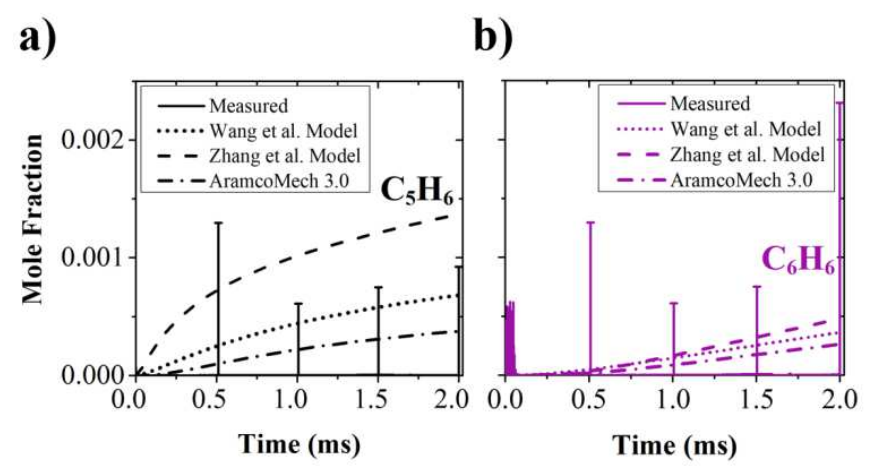

Fig. 6. Measured mole fractions versus time for (a) cyclopentadiene and (b) benzene in comparison to 369 two 1-butene specific kinetics models, from Wang et al. [22] and Zhang et al. [30], and also the 370 AramcoMech 3.0 model[40]. A shared ordinate axis is provided and is notably limited to a mole fraction 371 value of only 0.0025 . 
a)

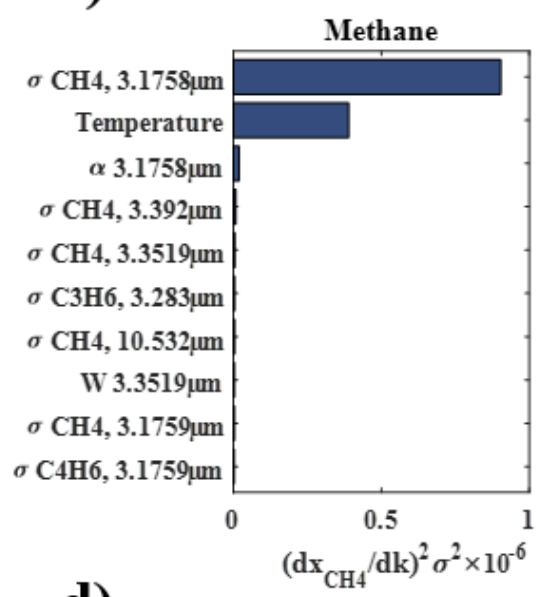

d)

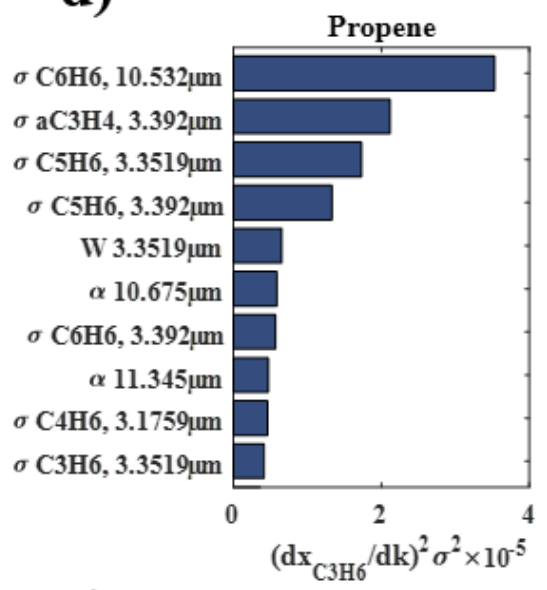

g)

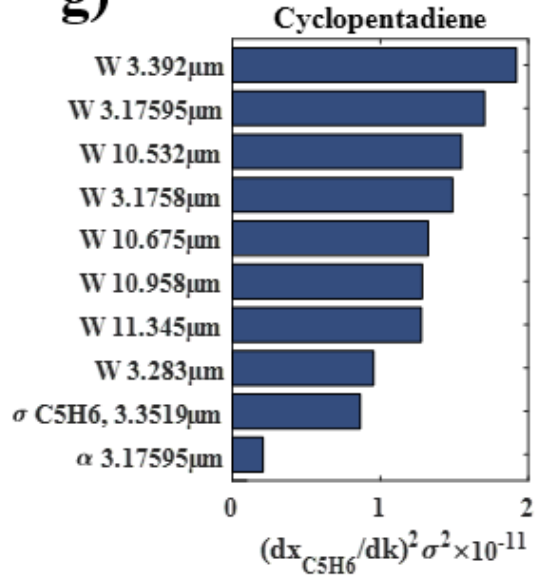

b)

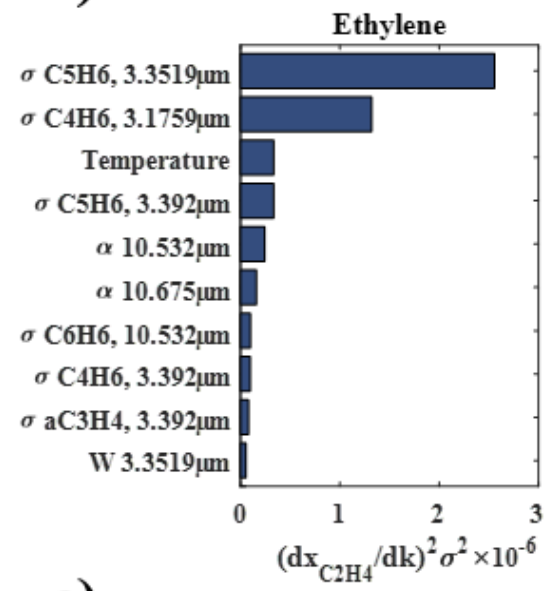

e)

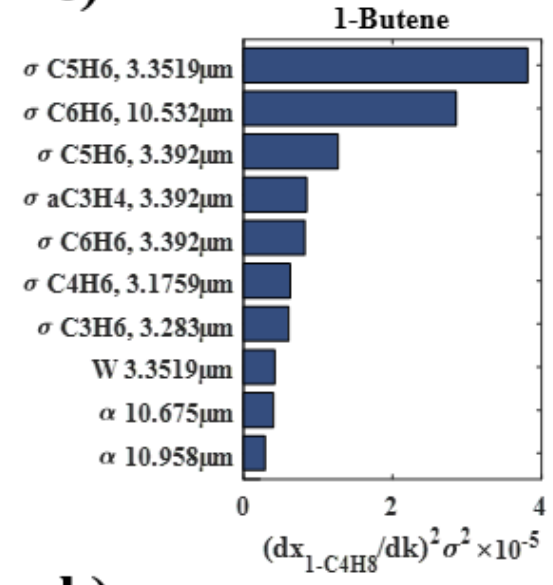

h)

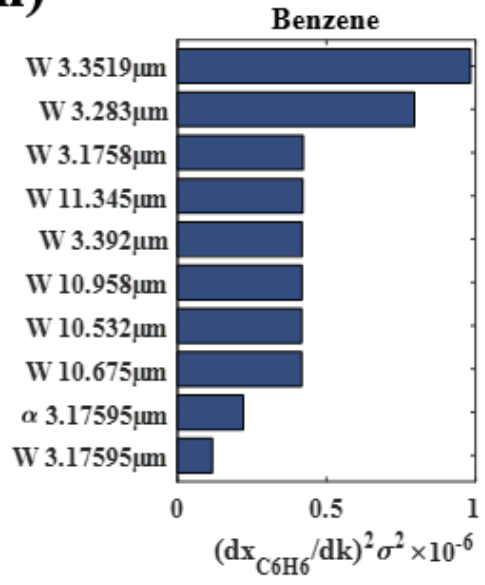

c)

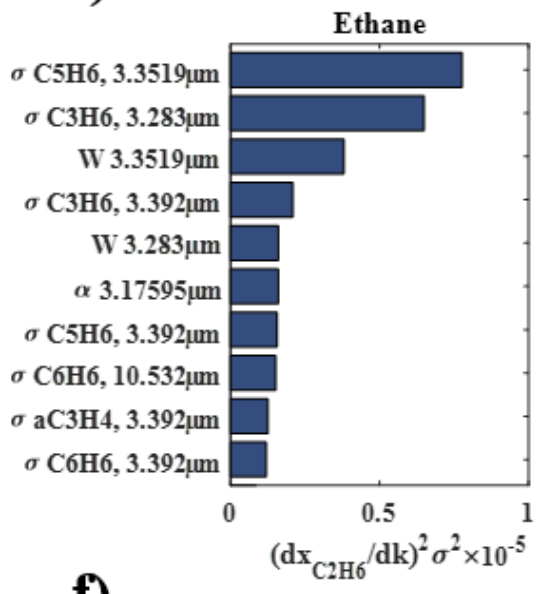

f)

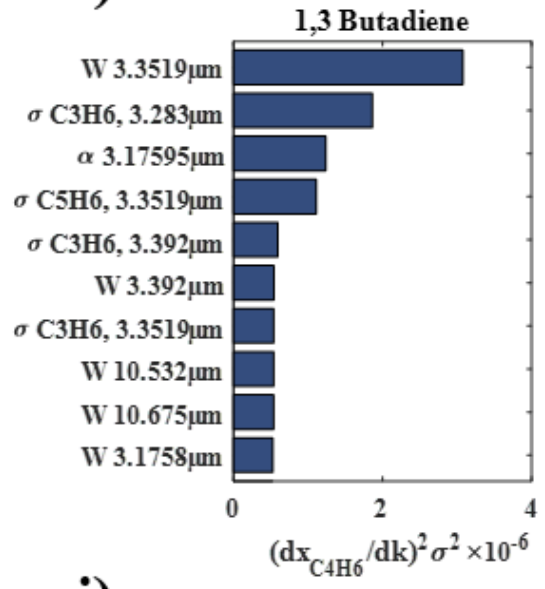

i)

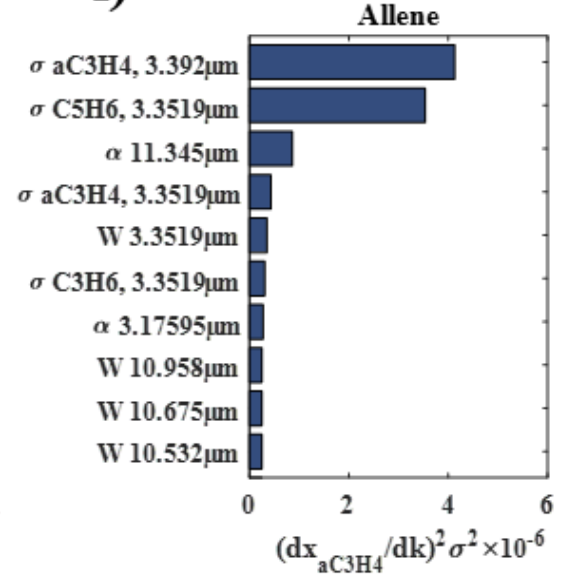

Fig. 7. The top 10squared uncertainty contributionsfrom cross-sections $(\sigma)$, absorbance

375 measurements $(\alpha)$, temperature, and weight parameter $(W)$ on each speciesmole fraction at 2 ms for (a) 
methane, (b) ethylene, (c) ethane, (d) propene, (e) 1-butene,(f) 1,3-butadiene,(g) cyclopentadiene, (h)

377 benzene, and (i) allene. $\left(d x_{i} / d k\right)$ refers to the derivative of the mole fraction with respect to each 378 variable of interest ( $k$ indicates either $\sigma, \alpha, T$, or $W$ ).

In order to identify system parameters for which reduced uncertainty is desired, the measurement uncertainty associated with each cross-section, absorbance, weight, and the temperature profile were evaluated and compared across all species. It was found that a few cross-section correlations were responsible for the majority of the uncertainty in the system. Accordingly, cross-section correlations with the largest contribution to the system uncertainty were identified as prominent targets for future research and cross-section database refinement. Specifically, these include cross-sections of minor species such as benzene and cyclopentadiene. Anuncertainty evaluation is presented in Fig.7 to indicate the 10 system parameters contributing the largest uncertainties to the measured mole fractions ofthe nine species included in the absorption cross-section matrix. Evident in Fig. 7 are the sensitivities to the crosssections of minor species and the relative insensitivity to the system-weighting parameters for all species. Although weighting parameters appear prominently in the sensitivities of benzene and cyclopentadiene, these species are present in such trace amounts thatthey cause no significant change in the measured mole fractions of other reported species. Recommended future studies include further absorption cross-section measurements of cyclopentadiene at $3.3519 \mu \mathrm{m}$, propene at $3.283 \mu \mathrm{m}$, and allene at $3.392 \mu \mathrm{m}$.

\section{Conclusion}

In the first demonstration of the laser absorption spectroscopy matrix speciation method proposed in 399 [21], shock tube time-histories of nine wavelengths were used to resolve species mole fractions during 400 the high-temperature pyrolysis of 1-butene. Because ethane was predicted to be an important pyrolysis product, a new wavelength at $3.3519 \mu \mathrm{m}$, sensitive to ethane absorption, was developed. This 
wavelength, along with eight additional wavelengths in the $3-4 \mu \mathrm{m}$ and $10-11 \mu \mathrm{m}$ regions, were used

403 to simultaneously solve for the time-histories of 1-butene, methane, ethylene, ethane, allene, propene,

404 1,3-butadiene, benzene, and cyclopentadieneduring 5\% 1-butene decomposition in argon at shock tube-

405 generated conditions of $1300 \mathrm{~K}$ and $1.8 \mathrm{~atm}$. To resolve the contributions of each species to each

406 wavelength, new cross-sections of relevant species were measured to supplement an existing database of

407 cross-section correlations.Overall, the resulting time-histories show good agreement with existing kinetic

408 models developed for 1-butene, especially the model proposed by Wang et al. [22]. Because the

409 pyrolysis offuels has been found to play an important role in their combustion pathways, the matrix

410 speciation method demonstrated here can be a useful tool in uncovering fueldecomposition behavior at

411 the short timescales relevant to combustion. With additional carefullychosen wavelengths to resolve

412 additional species, this framework can be readily extended from 1-butene to a range of more complex

413 hydrocarbon fuels with direct aerospace and automotive applications.

415 Appendix A: Sensitive ethane wavelength selection

\section{A.1. Survey of ethane absorption spectrum}

Selecting a wavelength for species-specific measurements requires consideration both of target- and interfering-species absorption, as well as the availability of narrow-linewidth, continuous-wave lasers.

Generally, because a single-wavelength diagnostic cannot distinguish between absorption from different species, substantial weight is placed on the interference-free criterion in selecting diagnostic lines.

423 Hence, the wavelength selected for ethane detection was intentionally chosen for use in a multi-

424 wavelength speciation method. Within this framework, although freedom from interference is preferred,

425 strict isolation from interfering species is not required. Rather, a wavelength was chosen at which 426 absorbance has unique sensitivity to the presence of ethane in the system. Put differently, the additional 
428 of all species, but especially ethane.

429

a)

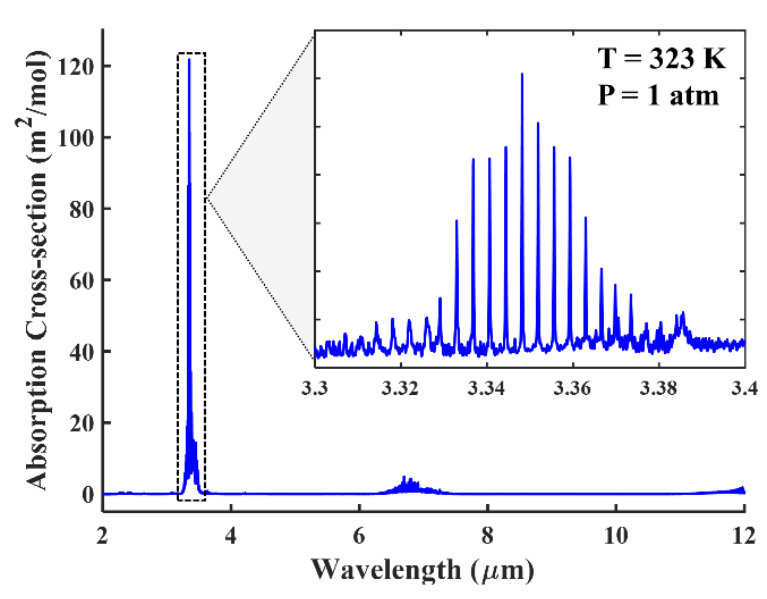

b)

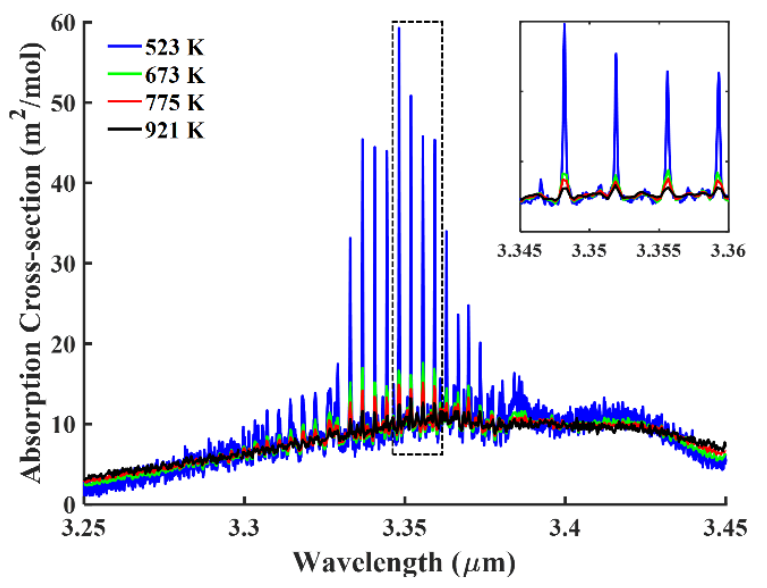

431

432

Fig. A.1. (a) PNNL-measured infrared absorption spectrum for ethane [41], and (b) KAUST-measured ethane spectra at elevated temperatures [27]. The $3.3 \mu \mathrm{m}$ region offers the strongest IR absorption, with narrow Q-branches collapsing into a broadband high-temperature feature.

Fig. A.1(a) shows the infrared spectrum of ethane at $323 \mathrm{~K}$ measured by Pacific Northwest National fundamental $\mathrm{CH}_{3}$ stretch modes $\left(v_{5}\right.$ and $\left.v_{7}\right)$ as well as numerous combination bands [42]. Although this region fortuitously coincides with compact, commercially available MIR lasers, it is also a common region of absorption for virtually all hydrocarbons. Such crowded absorption necessitates judicious wavelength selection to mitigate interference and optimize ethane sensitivity. Fig. A.1(b) gives a closer

442 view of the $3 \mu \mathrm{m}$ ethane spectrum at increasing temperatures, measured by KAUST with a Fourier 443 transform infrared spectrometer (FTIR) [27]. The strong, narrow peaks correspond to Q-branches of the $444 \quad v_{7}$ fundamental. As temperature increases, these structured features give way to the broadband absorption of many closelyspaced hot band transitions. That ethane behaves spectrally like a small 
molecule (structured) at low temperatures and a large molecule (broadband) at high temperatures

447 complicates the line-selection process by eliminating the possibility of an online/offline measurement

448 technique in high-temperature shock tube experiments. Nevertheless, a well-chosen wavelength with

449 minimal interference can yield sensitive ethane detection in a multi-wavelength, multi-species

450 measurement approach.

\section{A.2. Wavelength selection}

Because of its strong absorption and commercial laser accessibility, the $3.3 \mu \mathrm{m}$ region was chosen as the preferred spectral location for ethane sensing. Within this region, a systematic search was undertaken for the optimal combination of strong absorption and relative freedom from interference over a broad range of experimental conditions. In conducting the search, FTIR cross-section data from KAUST [27,43] and Klingbeil et al. [44]werecombinedwith line listsfrom HITRAN 2016 [45] to predict absorption from ethane and interferers methane, ethylene, acetylene, propene, and 1-butene. It should be noted that the HITRAN line list is incomplete and primarily tabulates Q-branch transitions in the $3.3 \mu \mathrm{m}$ region. It does not capture the large broadband absorbance that surrounds the Q-branch peaks but does yield reasonable predictions for the behavior of these peaks at the high temperatures of interest. searched for a stronglyabsorbing, interference-mitigating ethane wavelength. The wavelengths corresponding to Q-branch peaks were specifically studied for their favorable absorbance across a broad range of temperatures and pressures. Because both ethane and larger interfering species become relatively smooth at high temperatures, particular attention was paid to interference from discrete smallmolecule transitions, namely those of methane and ethylene. Ultimately, $3.35191 \mu \mathrm{m}$ was chosen as the

469 preferred wavelength with which to measure ethane. Fig. A.2 shows ethane cross-sections overlaid with 470 those of 1-butene, propene, methane, and ethylene at selected high temperatures where data exist. A 471 vertical line indicates the target wavelength selection. At this chosen wavelength, the advantageous 
472 combination of strong ethane cross-section with only weak interference from methane and ethylene is

473 evident. While 1-butene and propene have large cross-sections across the entire candidate region, their

474 contributions to measured absorbance were accounted for by the multi-wavelength measurement strategy

475 employed here.

476

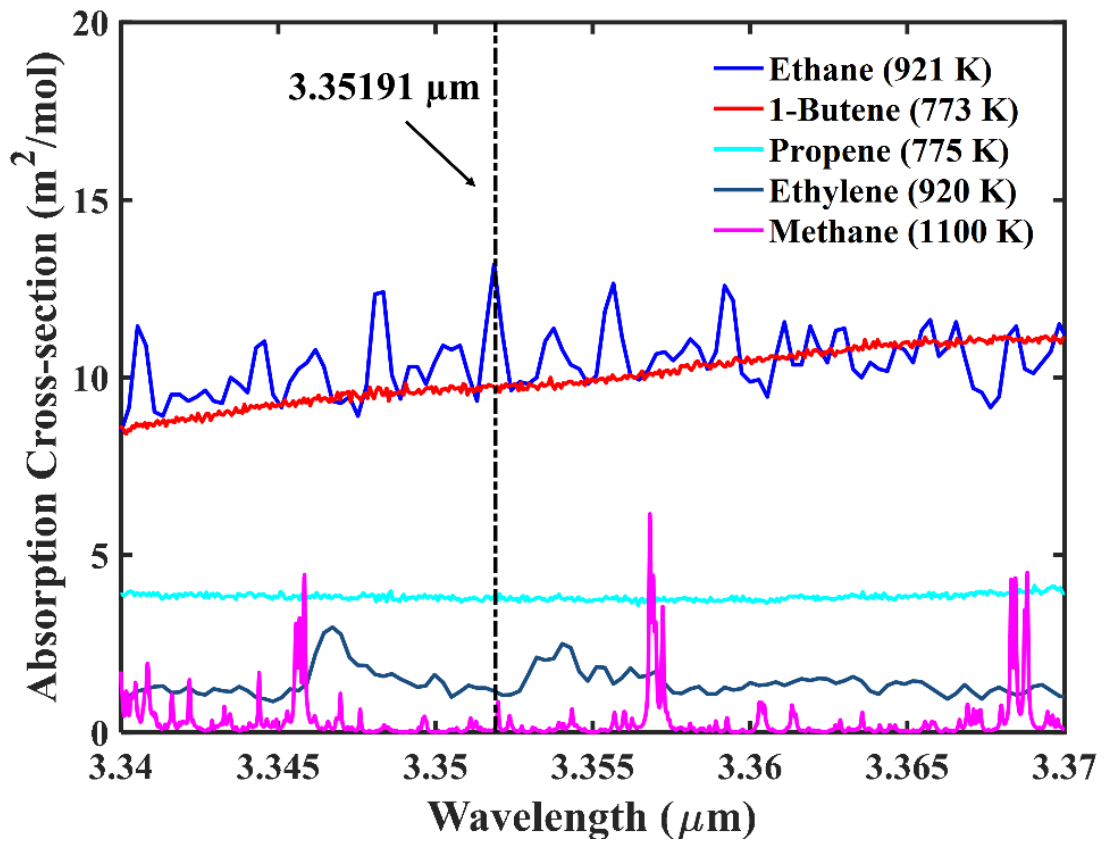

478

479 Fig. A.2. Ethane cross-sections compared with interference from 1-butene, propene, ethylene, and 480 methane at $1 \mathrm{~atm}$. The chosen wavelength for ethane detection, $3.35191 \mu \mathrm{m}$, is shown as a vertical line.

481 Methane interference was simulated with HITRAN 2016 [45], while ethane [27], 1-butene [44], propene 482 [44], and ethylene [27] cross-sections were taken from FTIR-measured literature data.

\section{Appendix B: Multi-wavelength cross-section matrix}

The majority of the absorption cross-section correlations and associated uncertainty directly 
butadiene, cyclopentadiene, and allene. Table B.1 presents a visualization of the absorption crosssection matrix used in this work. Cross-sections from the literature appear in gray and new crosssections from shock tube measurements are shown in white. Table B.2 presents these new cross-section correlations for individual species and wavelengths. Fig. B.1 shows the experimental data supporting the

\section{2}

493

494

495

496

497 498

\begin{tabular}{|l|c|c|c|c|c|c|c|c|c|}
\hline Wavelength & $\mathbf{C H}_{\mathbf{4}}$ & $\mathbf{C}_{\mathbf{2}} \mathbf{H}_{\mathbf{4}}$ & $\mathbf{C}_{\mathbf{2}} \mathbf{H}_{\mathbf{6}}$ & $\mathbf{C}_{\mathbf{3}} \mathbf{H}_{\mathbf{6}}$ & $\mathbf{a} \mathbf{C}_{\mathbf{3}} \mathbf{H}_{\mathbf{4}}$ & $\mathbf{1} \mathbf{C}_{\mathbf{4}} \mathbf{H}_{\mathbf{8}}$ & $\mathbf{C}_{\mathbf{4}} \mathbf{H}_{\mathbf{6}}$ & $\mathbf{C}_{\mathbf{5}} \mathbf{H}_{\mathbf{6}}$ & $\mathbf{C}_{\mathbf{6}} \mathbf{H}_{\mathbf{6}}$ \\
\hline $\mathbf{3 . 1 7 5 8} \boldsymbol{\mu m}$ & $\sigma_{1,1}$ & $\sigma_{1,2}$ & $\sigma_{1,3}$ & $\sigma_{1,4}$ & $\sigma_{1,5}$ & $\sigma_{1,6}$ & $\sigma_{1,7}$ & $\sigma_{1,8}$ & $\sigma_{1,9}$ \\
\hline $\mathbf{3 . 2 8 3 \mu \mathbf { m }}$ & $\sigma_{2,1}$ & $\sigma_{2,2}$ & $\sigma_{2,3}$ & $\sigma_{2,4}$ & $\sigma_{2,5}$ & $\sigma_{2,6}$ & $\sigma_{2,7}$ & $\sigma_{2,8}$ & $\sigma_{2,9}$ \\
\hline $\mathbf{3 . 3 5 1 9} \boldsymbol{\mu m}$ & $\sigma_{4,1}$ & $\sigma_{4,2}$ & $\sigma_{4,3}$ & $\sigma_{4,4}$ & $\sigma_{4,5}$ & $\sigma_{4,6}$ & $\sigma_{4,7}$ & $\sigma_{4,8}$ & $\sigma_{4,9}$ \\
\hline $\mathbf{3 . 3 9 2} \boldsymbol{\mu m}$ & $\sigma_{5,1}$ & $\sigma_{5,2}$ & $\sigma_{5,3}$ & $\sigma_{5,4}$ & $\sigma_{5,5}$ & $\sigma_{5,6}$ & $\sigma_{5,7}$ & $\sigma_{5,8}$ & $\sigma_{5,9}$ \\
\hline $\mathbf{1 0 . 5 3 2} \boldsymbol{\mu m}$ & $\sigma_{6,1}$ & $\sigma_{6,2}$ & $\sigma_{6,3}$ & $\sigma_{6,4}$ & $\sigma_{6,5}$ & $\sigma_{6,6}$ & $\sigma_{6,7}$ & $\sigma_{6,8}$ & $\sigma_{6,9}$ \\
\hline $\mathbf{1 0 . 6 7 5} \boldsymbol{\mu m}$ & $\sigma_{8,1}$ & $\sigma_{8,2}$ & $\sigma_{8,3}$ & $\sigma_{8,4}$ & $\sigma_{8,5}$ & $\sigma_{8,6}$ & $\sigma_{8,7}$ & $\sigma_{8,8}$ & $\sigma_{8,9}$ \\
\hline $\mathbf{1 0 . 9 5 8} \boldsymbol{\mu m}$ & $\sigma_{9,1}$ & $\sigma_{9,2}$ & $\sigma_{9,3}$ & $\sigma_{9,4}$ & $\sigma_{9,5}$ & $\sigma_{9,6}$ & $\sigma_{9,7}$ & $\sigma_{9,8}$ & $\sigma_{9,9}$ \\
\hline $\mathbf{1 1 . 3 5} \boldsymbol{\mu m}$ & $\sigma_{10,1}$ & $\sigma_{10,2}$ & $\sigma_{10,3}$ & $\sigma_{10,4}$ & $\sigma_{10,5}$ & $\sigma_{10,6}$ & $\sigma_{10,7}$ & $\sigma_{10,8}$ & $\sigma_{10,9}$ \\
\hline
\end{tabular}

Table B.1. Cross-section matrix used for 1-butene speciation. Gray cells reference cross-sections published previously in the literature. White cells indicate new cross-section correlations. correlations of Table B.2. In certain cases where absorption cross-sections were unavailable, approximations are reported from extrapolations of available FTIR and broadlytuned laser [46] data. Nonetheless, the pyrolysis time-histories reported here were shown to be insensitive to these few approximated cross-sections. 
507 Table B.2. Cross-section correlation table for new correlations.

\begin{tabular}{|c|c|c|c|c|c|}
\hline Species & Cell & $\begin{array}{l}\text { Fitted value of cross-section }\left(\sigma\left[\frac{m 2}{m o l}\right]\right) \text { vs. } \\
\text { temperature }(T[K]) \text { in }\end{array}$ & $\begin{array}{l}\text { Standard error } \\
(\boldsymbol{n}=\# \text { of samples })\end{array}$ & Reference & Notes and literature correlations \\
\hline \multicolumn{6}{|c|}{ Cross-sections at $3.1758 \mu \mathrm{m}$} \\
\hline$\overline{\mathrm{C}_{2} \mathrm{H}_{6}}$ & $1,1,3$ & $\begin{array}{l}\sigma=a_{0}+a_{1} T \\
a_{0}=0.14548 \\
a_{1}=-3.37354 E-5\end{array}$ & $\begin{array}{l}n=30 \\
v=28 \\
R S S=0.05137 \\
t_{95}=2.048 \\
s_{T T}=3.68 E 6 \\
\bar{T}=1109.078\end{array}$ & New & $\begin{array}{l}\text { Correlation valid between } 300-1300 \\
K .\end{array}$ \\
\hline$\overline{a C_{3} H_{4}}$ & 1,5 & Approximately zero & & {$[37,41]$} & Approximately zero. \\
\hline $\mathrm{C}_{4} \mathrm{H}_{6}$ & 1,7 & $\begin{array}{l}\sigma=a_{0}+a_{1} T \\
a_{0}=0.98562 \\
a_{1}=-2.1536 E-4\end{array}$ & $\begin{array}{l}n=6 \\
v=4 \\
R S S=0.04421 \\
t_{95}=2.776 \\
s_{T T}=5.3 E 5 \\
\bar{T}=1067.676\end{array}$ & New & $\begin{array}{l}\text { Correlation valid between } 700-1550 \\
K .\end{array}$ \\
\hline $\mathrm{C}_{5} \mathrm{H}_{6}$ & 1,8 & $\begin{array}{l}\sigma=a_{0}+a_{1} T \\
a_{0}=0.10094 \\
a_{1}=4.5048 E-5\end{array}$ & Approximation & Approximation & $\begin{array}{l}\text { Assumed to be } 1 / 4 \text { the absorption } \\
\text { cross-section as } 3.392 \mu m . \text { Low } \\
\text { absorption cross-section expected. }\end{array}$ \\
\hline 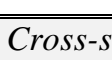 & & $\overline{17595 \mu \mathrm{m}}$ & & & \\
\hline
\end{tabular}




\begin{tabular}{|c|c|c|c|c|c|}
\hline $\mathrm{C}_{2} \mathrm{H}_{6}$ & 2,3 & $\begin{array}{l}\sigma=a_{0}+a_{1} T \\
a_{0}=0.14548 \\
a_{1}=-3.37354 E-5\end{array}$ & $\begin{array}{l}n=30 \\
v=28 \\
R S S=0.05137 \\
t_{95}=2.048 \\
s_{T T}=3.68 E 6 \\
\bar{T}=1109.078\end{array}$ & New & $\begin{array}{l}\text { Assumed to be the same as } 3.1758 \mu \mathrm{m} \text {. } \\
\text { Correlation valid between } 300-1300 \\
\text { K. }\end{array}$ \\
\hline$a \mathrm{C}_{3} \mathrm{H}_{4}$ & 2,5 & Approximately zero & & {$[37,41]$} & Approximately zero. \\
\hline $\mathrm{C}_{4} \mathrm{H}_{6}$ & 2,7 & $\begin{array}{l}\sigma=a_{0}+a_{1} T \\
a_{0}=0.98562 \\
a_{1}=-2.1536 E-4\end{array}$ & $\begin{array}{l}n=6 \\
v=4 \\
R S S=0.04421 \\
t_{95}=2.776 \\
s_{T T}=5.3 E 5 \\
\bar{T}=1067.676\end{array}$ & New & $\begin{array}{l}\text { Assumed to be the same as } 3.1758 \mu \mathrm{m} \text {. } \\
\text { Correlation valid between } 700-1550 \\
\mathrm{~K} .\end{array}$ \\
\hline $\mathrm{C}_{5} \mathrm{H}_{6}$ & 2,8 & $\begin{array}{l}\sigma=a_{0}+a_{1} T \\
a_{0}=0.10094 \\
a_{1}=4.5048 E-5\end{array}$ & Approximation & Approximation & $\begin{array}{l}\text { Assumed to be } 1 / 4 \text { the absorption } \\
\text { cross-section at } 3.392 \mu m . \text { Low } \\
\text { absorption cross-section expected. }\end{array}$ \\
\hline \multicolumn{6}{|c|}{ Cross-sections at $3.283 \mu \mathrm{m}$} \\
\hline 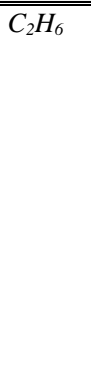 & 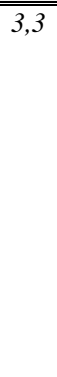 & $\begin{array}{l}\sigma=a_{0}+a_{1} T+a_{2} T^{2} \\
a_{0}=2.08095 \\
a_{1}=-0.00203 \\
a_{2}=5.35068 E-7\end{array}$ & $\begin{array}{l}n=39 \\
v=36 \\
R S S=0.1843 \\
t_{95}=2.042 \\
s_{T T}=4.21 E 6 \\
\bar{T}=1101.33\end{array}$ & New & $\begin{array}{l}\text { Correlation valid between } 600-1800 \\
K \text {. }\end{array}$ \\
\hline$a C_{3} H_{4}$ & 3,5 & Approximately zero & & {$[37,41]$} & Approximately zero. \\
\hline $\mathrm{C}_{4} \mathrm{H}_{6}$ & 3,7 & $\begin{array}{l}\sigma=a_{0}+a_{1} T+a_{2} T^{2} \\
a_{0}=-0.46373 \\
a_{1}=0.00719 \\
a_{2}=-3.13536 E-6\end{array}$ & $\begin{array}{l}n=6 \\
v=3 \\
R S S=0.01955 \\
t_{95}=3.182 \\
s_{T T}=5.30 E 5 \\
\bar{T}=1067.676\end{array}$ & New & $\begin{array}{l}\text { Correlation valid between } 700-1550 \\
K .\end{array}$ \\
\hline
\end{tabular}




\begin{tabular}{|c|c|c|c|c|c|}
\hline $\mathrm{C}_{5} \mathrm{H}_{6}$ & 3,8 & $\begin{array}{l}\sigma=a_{0}+a_{1} T \\
a_{0}=0.40375 \\
a_{1}=1.8019 E-4\end{array}$ & Approximation & Approximation & $\begin{array}{l}\text { Assumed to be the same as the } \\
\text { absorption cross-section at } 3.392 \mu m \text {. } \\
\text { Low absorption cross-section } \\
\text { expected. }\end{array}$ \\
\hline \multicolumn{6}{|c|}{ Cross-sections at $3.3519 \mu \mathrm{m}$} \\
\hline$\overline{\mathrm{C} \mathrm{CH}_{4}}$ & 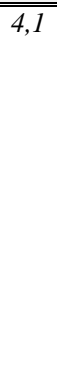 & $\begin{array}{l}\sigma=a_{0}+a_{1} T+a_{2} T^{2} \\
a_{0}=-3.88202 \\
a_{1}=0.00861 \\
a_{2}=-2.79276 E-6\end{array}$ & $\begin{array}{l}n=16 \\
v=13 \\
R S S=0.65252 \\
t_{95}=2.160 \\
s_{T T}=2.64 E 6 \\
\bar{T}=1214.97\end{array}$ & New & $\begin{array}{l}\text { Correlation valid between } 600-2100 \\
K \text {. }\end{array}$ \\
\hline $\mathrm{C}_{2} \mathrm{H}_{4}$ & 4,2 & $\begin{array}{l}\sigma=a_{0}+a_{1} T+a_{2} T^{2} \\
a_{0}=0.79448 \\
a_{1}=5.36859 E-4 \\
a_{2}=-2.13847 E-7\end{array}$ & $\begin{array}{l}n=8 \\
v=5 \\
R S S=0.02818 \\
t_{95}=2.571 \\
s_{T T}=1.43 E 6 \\
\bar{T}=1214.7\end{array}$ & New & $\begin{array}{l}\text { Correlation valid between } 700-2000 \\
K \text {. }\end{array}$ \\
\hline $\mathrm{C}_{2} \mathrm{H}_{6}$ & 4,3 & $\begin{array}{l}\left.\sigma=a_{0}+a_{1} \exp -\frac{T-x_{0}}{b_{1}}\right) \\
a_{0}=4.03848 \\
a_{1}=47.26708 \\
b_{1}=679.65013 \\
x_{0}=251.60459\end{array}$ & $\begin{array}{l}n=28 \\
v=24 \\
R S S=709.4 \\
t_{95}=2.064 \\
s_{T T}=3.79 E 6 \\
\bar{T}=1156.89\end{array}$ & New & $\begin{array}{l}\text { Correlation valid between } 600-2000 \\
\text { K. Slight pressure dependence } \\
\text { observed below } 1000 \mathrm{~K} .\end{array}$ \\
\hline $\mathrm{C}_{3} \mathrm{H}_{6}$ & 4,4 & $\begin{array}{l}\left.\sigma=a_{0}+a_{1} \exp -\frac{T-x_{0}}{b_{1}}\right) \\
a_{0}=2.5978 \\
a_{1}=2.9384 \\
b_{1}=343.40548 \\
x_{0}=303.0564\end{array}$ & $\begin{array}{l}n=12 \\
v=8 \\
R S S=1.31982 \\
t_{95}=2.306 \\
s_{T T}=1.43 E 6 \\
\bar{T}=820.912\end{array}$ & New \&[44] & $\begin{array}{l}\text { Correlation valid between } 300-1600 \\
K \text {. }\end{array}$ \\
\hline$a C_{3} H_{4}$ & 4,5 & $\begin{array}{l}\sigma=a_{0}+a_{1} T+a_{2} T^{2} \\
a_{0}=0.34 \\
a_{1}=0.0012 \\
a_{2}=-5.7989\end{array}$ & Approximation & {$[37,41]$} & $\begin{array}{l}\text { Approximated as } 1 / 3 \text { of the absorption } \\
\text { cross-section of } 1,3-\mathrm{C}_{4} \mathrm{H}_{6} \text { based on } \\
\text { FTIR data up to } 510 \mathrm{~K} \text {. Uncertainty } \\
\text { estimated as } 1,3-\mathrm{C}_{4} \mathrm{H}_{6} \text { uncertainty. }\end{array}$ \\
\hline
\end{tabular}




\begin{tabular}{|c|c|c|c|c|c|}
\hline $1 \mathrm{C}_{4} \mathrm{H}_{8}$ & 4,6 & $\begin{array}{l}\sigma=a_{0}+a_{1} T \\
a_{0}=14.91918 \\
a_{1}=-0.00678\end{array}$ & $\begin{array}{l}n=8 \\
v=6 \\
R S S=1.14718 \\
t_{95}=2.447 \\
s_{T T}=8.02 E 5 \\
\bar{T}=1020.51675\end{array}$ & New & $\begin{array}{l}\text { Correlation valid between } 600-1700 \\
K .\end{array}$ \\
\hline $\mathrm{C}_{4} \mathrm{H}_{6}$ & 4,7 & $\begin{array}{l}\sigma=a_{0}+a_{1} T+a_{2} T^{2} \\
a_{0}=1.02567 \\
a_{1}=0.00369 \\
a_{2}=-1.73969 E-6\end{array}$ & $\begin{array}{l}n=6 \\
v=3 \\
R S S=0.00225 \\
t_{95}=3.182 \\
s_{T T}=5.30 E 5 \\
\bar{T}=1067.676\end{array}$ & $\mathrm{New}$ & $\begin{array}{l}\text { Correlation valid between } 700-1550 \\
K .\end{array}$ \\
\hline $\mathrm{C}_{5} \mathrm{H}_{6}$ & 4,8 & $\begin{array}{l}\sigma=a_{0}+a_{1} T \\
a_{0}=0.40375 \\
a_{1}=1.8019 E-4\end{array}$ & Approximation & Approximation & $\begin{array}{l}\text { Assumed to be the same as the } \\
\text { absorption cross-section at } 3.392 \mu \mathrm{m} \text {. } \\
\text { Low absorption cross-section } \\
\text { expected. }\end{array}$ \\
\hline $\mathrm{C}_{6} \mathrm{H}_{6}$ & 4,9 & Approximately zero & Approximation & [41] & Approximately zero. \\
\hline \multicolumn{6}{|c|}{ Cross-sections at $3.392 \mu \mathrm{m}$} \\
\hline$a C_{3} H_{4}$ & 5,5 & Approximately zero & Approximation & {$[37,41]$} & Approximately zero. \\
\hline $\mathrm{C}_{4} \mathrm{H}_{6}$ & 5,7 & $\begin{array}{l}\sigma=a_{0}+a_{1} T \\
a_{0}=1.06643 \\
a_{1}=4.80739 E-4\end{array}$ & $\begin{array}{l}n=11 \\
v=9 \\
R S S=0.08677 \\
t_{95}=2.262 \\
s_{T T}=1.67 E 5 \\
\bar{T}=1251.222\end{array}$ & New & $\begin{array}{l}\text { Correlation valid between } 1100-1500 \\
K .\end{array}$ \\
\hline
\end{tabular}




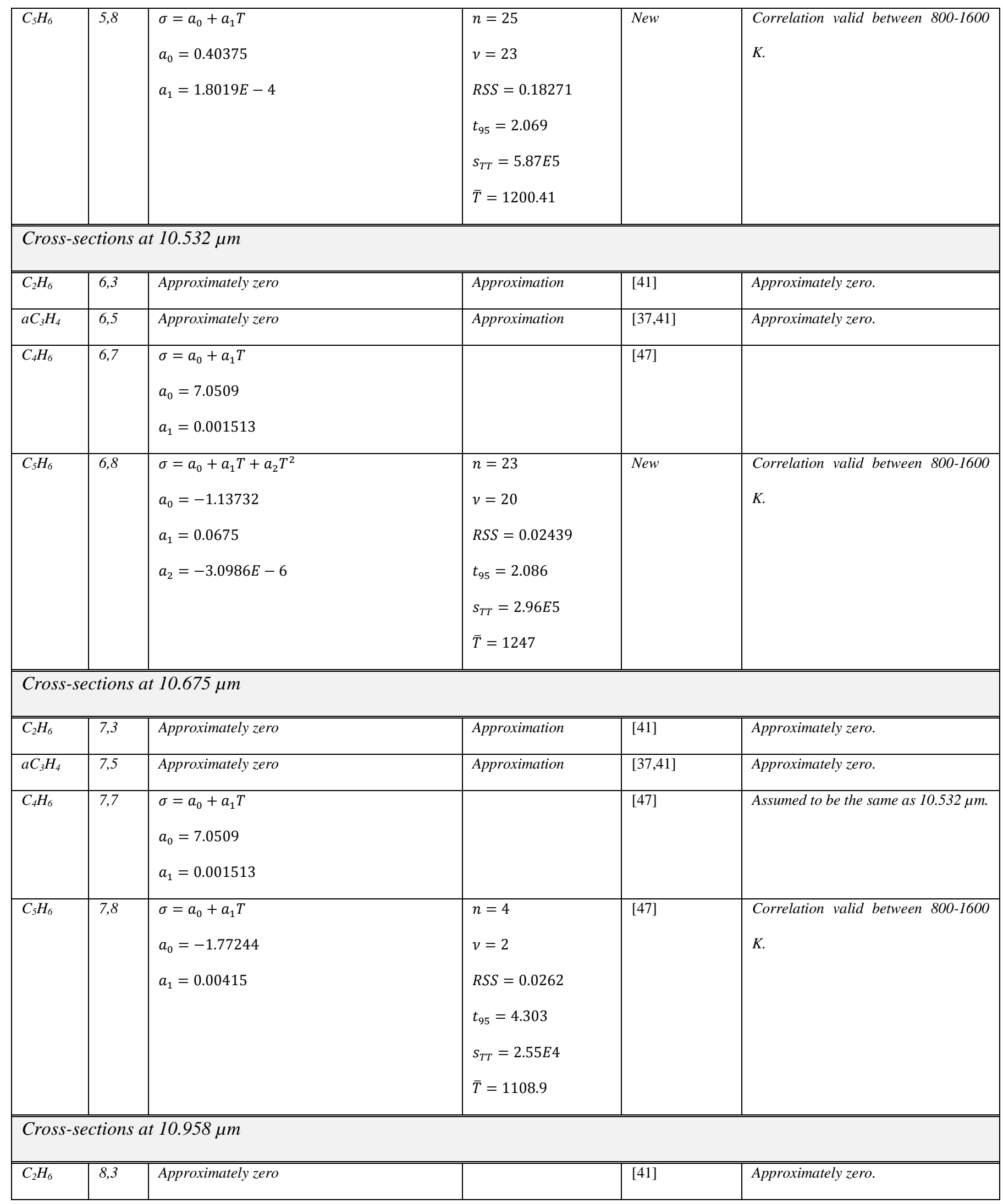




\begin{tabular}{|c|c|c|c|c|c|}
\hline$a C_{3} H_{4}$ & 8,5 & $\begin{array}{l}\sigma=a_{0}+a_{1} T+a_{2} T^{2} \\
a_{0}=7.2996 \\
a_{1}=-0.00478 \\
a_{2}=1.23919 E-6\end{array}$ & $\begin{array}{l}n=5 \\
v=2 \\
R S S=0.02565 \\
t_{95}=4.303 \\
s_{T T}=3.07 E 5 \\
\bar{T}=1257\end{array}$ & {$[48]$} & $\begin{array}{l}\text { Approximated as having the same } \\
\text { absorption at } 10.958 \mu \mathrm{m} \text { as } 10.962 \\
\mu \mathrm{m} \text { due to broad features and using } \\
\text { cross-sections measured by Chrystie } \\
\text { et al. [48]. Correlation valid between } \\
900-1650 \mathrm{~K} \text {. }\end{array}$ \\
\hline $\mathrm{C}_{4} \mathrm{H}_{6}$ & 8,7 & $\begin{array}{l}\sigma=a_{0}+a_{1} T \\
a_{0}=9.86671 \\
a_{1}=-0.00287\end{array}$ & $\begin{array}{l}n=4 \\
v=2 \\
R S S=0.37894 \\
t_{95}=4.303 \\
s_{T T}=4.12 E 5 \\
\bar{T}=1037\end{array}$ & {$[46,47]$} & $\begin{array}{l}\text { Correlation valid between } 600 \mathrm{~K} \text { and } \\
1600 \mathrm{~K} .\end{array}$ \\
\hline $\mathrm{C}_{5} \mathrm{H}_{6}$ & 8,8 & $\begin{array}{l}\sigma=a_{0}+a_{1} T+a_{2} T^{2} \\
a_{0}=2.49963 \\
a_{1}=0.00303 \\
a_{2}=-1.8117 E-6\end{array}$ & $\begin{array}{l}n=8 \\
v=5 \\
R S S=0.00113 \\
t_{95}=2.571 \\
s_{T T}=1.31 E 5 \\
\bar{T}=1242\end{array}$ & [47] & $\begin{array}{l}\text { Correlation valid between } 1000 \mathrm{~K} \text { and } \\
1500 \mathrm{~K} .\end{array}$ \\
\hline 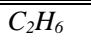 & $9,9,3$ & Approximately zero & & [41] & Approximately zero. \\
\hline$a \mathrm{C}_{3} \mathrm{H}_{4}$ & 9,5 & $\begin{array}{l}\sigma=a_{0}+a_{1} T \\
a_{0}=1.9421 \\
a_{1}=0.0010984\end{array}$ & Approximation & [37] & $\begin{array}{l}\text { Approximated as having absorption } \\
\text { cross-section as 1,3-butadiene at } \\
11.345 \mu \mathrm{m} \text { based on inspection of } \\
\text { FTIR spectra up to } 510 \mathrm{~K} \text {. } \\
\text { Uncertainty estimated as } 1,3-\mathrm{C}_{4} \mathrm{H}_{6} \\
\text { uncertainty. }\end{array}$ \\
\hline $\mathrm{C}_{4} \mathrm{H}_{6}$ & 9,7 & $\begin{array}{l}\sigma=a_{0}+a_{1} T \\
a_{0}=1.9421 \\
a_{1}=0.0010984\end{array}$ & & {$[46,47]$} & \\
\hline
\end{tabular}




\begin{tabular}{|l|l|l|l|l|l|}
\hline$C_{5} H_{6}$ & 9,8 & $\sigma=a_{0}+a_{1} T+a_{2} T^{2}+a_{3} T^{3}$ & $n=22$ & New & Correlation valid between 800 K and \\
& & $a_{0}=-73.92686$ & $v=18$ & \\
& & $a_{1}=0.20195$ & $R S S=0.14132$ \\
& $a_{2}=-1.64928 E-4$ & $t_{95}=2.101$ & \\
& & $a_{3}=4.32314 E-8$ & $s_{T T}=2.15 E 5$ & \\
& & & $T=1263.73$ & \\
& & & & \\
\hline
\end{tabular}



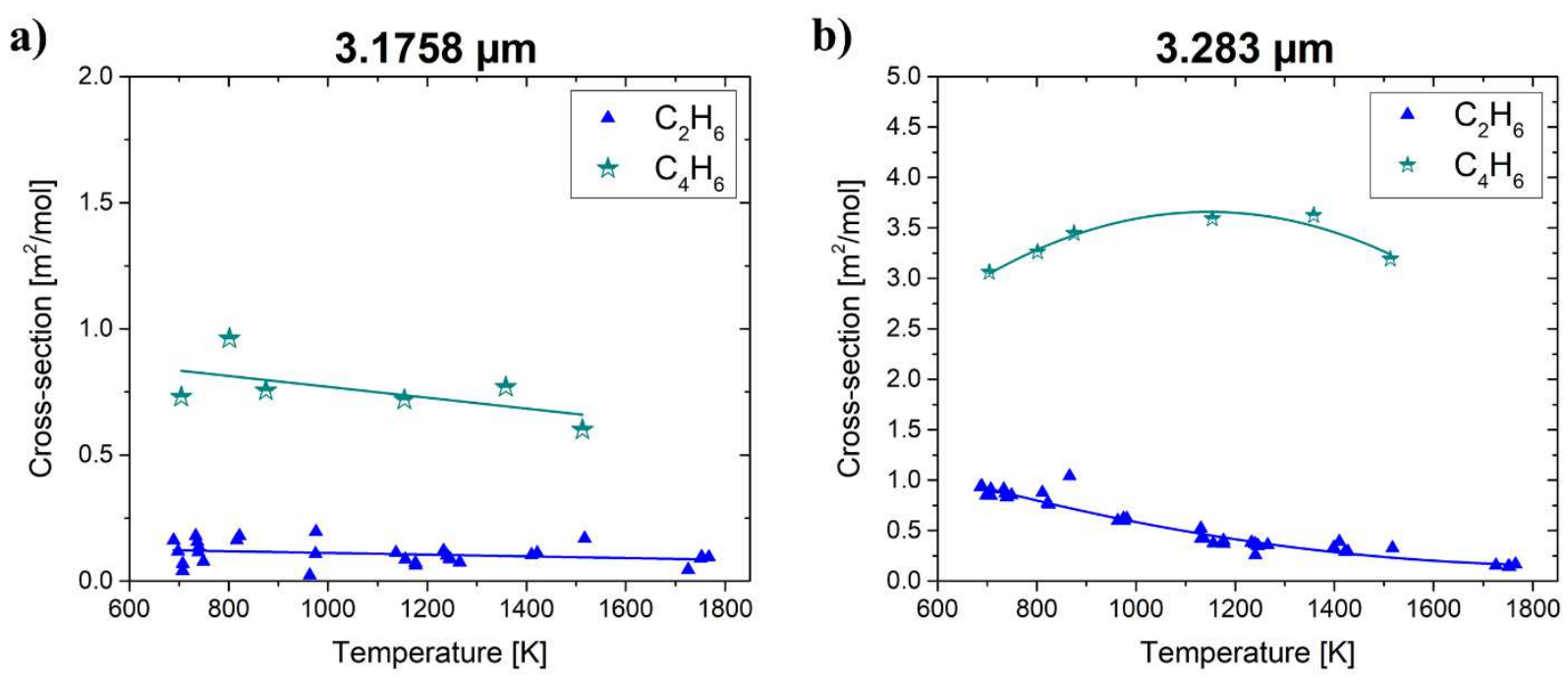

c)

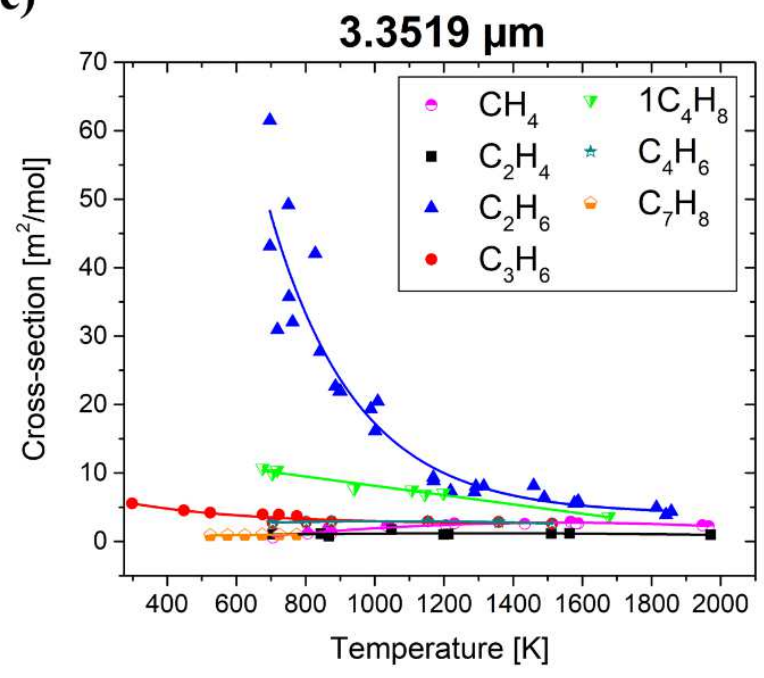

d)

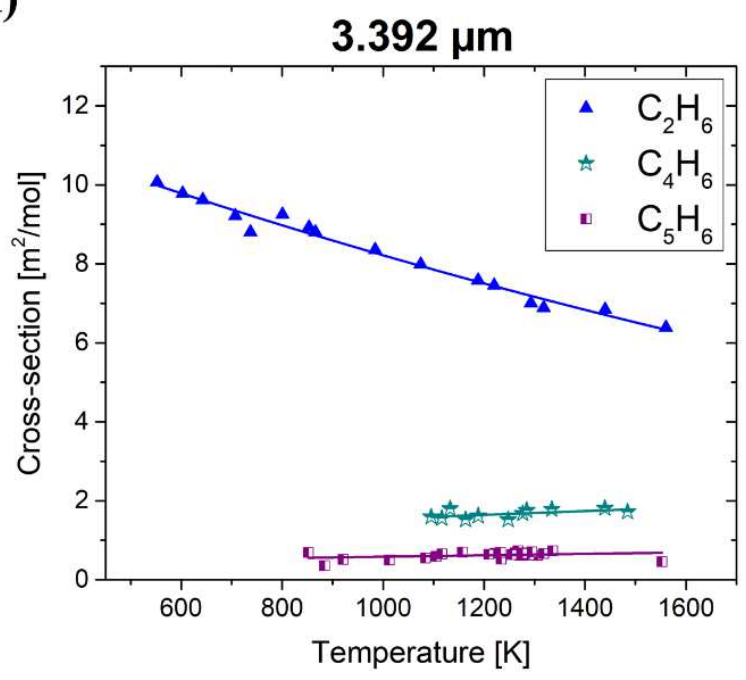

513

514 Fig. B.1. Experimental cross-section measurements to complete the cross-section matrix. (a)

515 Measurements at $3.1758 \mu \mathrm{m}$, (b) $3.283 \mu \mathrm{m}$, (c) $3.3519 \mu \mathrm{m}$, and (d) $3.392 \mu \mathrm{m}$.

516

517

518 


\section{Acknowledgements}

520 This work was funded by the US Federal Aviation Administration (FAA) Office of Environment and

521 Energy as a part of ASCENT Project 25 under FAA Award Number: 13-C-AJFE-SU-016. Any

522 opinions, findings, and conclusions or recommendations expressed in this material are those of the

523 authors and do not necessarily reflect the views of the FAA or other ASCENT sponsors. Authors N. H.

524 Pinkowski and Séan J. Cassady acknowledge financial support from the Department of Defense through 525 the National Defense Science and Engineering Graduate (NDSEG) Fellowship.

527 References

528

529 [1] Hanson RK, Davidson DF. Recent advances in laser absorption and shock tube methods for

[2] Xu R, Wang K, Banerjee S, Shao J, Parise T, Zhu Y, et al. A physics-based approach to modeling

[3] Wang H, Xu R, Wang K, Bowman CT, Hanson RK, Davidson DF, et al. A physics-based approach to modeling real-fuel combustion chemistry - I. Evidence from experiments, and thermodynamic, chemical kinetic and statistical considerations. Combust Flame 2018;193:502_ 19. doi:10.1016/j.combustflame.2018.03.019.

[4] Xu R, Wang K, Banerjee S, Shao J, Parise T, Zhu Y, et al. A physics-based approach to modeling real-fuel combustion chemistry - III. Reaction kinetic model of JP10. Combust Flame 2018;193:520-37. doi:10.1016/j.combustflame.2018.03.021.

[5] Wang K, Xu R, Parise T, Shao J, Movaghar A, Lee DJ, et al. A physics-based approach to modeling real-fuel combustion chemistry - IV. HyChem modeling of combustion kinetics of a bio-derived jet fuel and its blends with a concentional Jet A. Combust Flame 2018;198:477-89. 
doi:10.1016/j.combustflame.2018.03.021.

546 [6] Hanson RK, Davidson DF. Advances in shock tube techniques for fundamental studies of 547 combustion kinetics. 25th ICDERS 2015:1-5.

548 [7] Goldenstein CS, Spearrin RM, Jeffries JB, Hanson RK. Infrared laser-absorption sensing for 549 combustion gases. Prog Energy Combust Sci 2017;60:132-76. doi:10.1016/j.pecs.2016.12.002.

550 [8] Olson DB, Mallard WG, Gardiner WC. High Temperature Absorption of the $3.39 \mu \mathrm{m}$ He-Ne

$551 \quad$ Laser Line by Small Hydrocarbons. Appl Spectrosc 1978;32:489-93.

552 doi:10.1366/000370278774330892.

553 [9] Hidaka Y, Higashihara T, Ninomiya N, Oki T, Kawano H. Thermal isomerization and 554 decomposition of 1,2 $\square$ butadiene in shock waves. Int J Chem Kinet 1995;27:331-41. 555 doi:10.1002/kin.550270404.

556 [10] Koike T, Gardiner WC. High-Temperature Absorption of the $3.39 \mu \mathrm{m}$ He-Ne Laser Line by 557 Acetylene, Ethylene, and Propylene. Appl Spectrosc 1980;34:81-4.

558 doi:10.1366/0003702804730899.

559 [11] Tsuboi T, Inomata K, Tsunoda Y, Isobe A, Nagaya K. Light Absorption by Hydrocarbon $560 \quad$ Molecules at 3.392 $\mu \mathrm{m}$ of He-Ne Laser. Jpn J Appl Phys 1985;24:8-13.

561 [12] Sur R, Wang S, Sun K, Davidson DF, Jeffries JB, Hanson RK. High-sensitivity interference-free 562 diagnostic for measurement of methane in shock tubes. J Quant Spectrosc Radiat Transf $563 \quad 2015 ; 156: 80-7$. doi:10.1016/j.jqsrt.2015.01.023.

564 [13] Pyun SH, Cho J, Davidson DF, Hanson RK. Interference-free mid-IR laser absorption detection 565 of methane. Meas Sci Technol 2011;22. doi:10.1088/0957-0233/22/2/025303.

566 [14] Pilla GL, Davidson DF, Hanson RK. Shock tube/laser absorption measurements of ethylene time567 histories during ethylene and n-heptane pyrolysis. Proc Combust Inst 2011;33:333-40. 568 doi:10.1016/j.proci.2010.06.146.

569 [15] MacDonald ME, Ren W, Zhu Y, Davidson DF, Hanson RK. Fuel and Ethylene Measurements 570 during n-dodecane, methylcyclohexane, and iso-cetane pyrolysis in shock tubes. Fuel 
2013;103:1060-8. doi:10.1016/j.fuel.2012.09.068.

572 [16] Ren W, Davidson DF, Hanson RK. IR Laser Absorption Diagnostic for C2H4 in Shock Tube Kinetics Studies. Int J Chem Kinet 2011;129. doi:10.1002/kin.20599.

574 [17] Stranic I, Hanson RK. Laser absorption diagnostic for measuring acetylene concentrations in

[18] Spearrin RM, Li S, Davidson DF, Jeffries JB, Hanson RK. High-temperature iso-butene absorption diagnostic for shock tube kinetics using a pulsed quantum cascade laser near $11.3 \mu \mathrm{m}$. Proc Combust Inst 2015;35:3645-51. doi:10.1016/j.proci.2014.04.002.

[19] Parise TC, Davidson DF, Hanson RK. Development of a two-wavelength IR laser absorption diagnostic for propene and ethylene. Meas Sci Technol 2018;29. doi:10.1088/1361-6501/aab02b.

[20] Parise T, Davidson DF, Hanson RK. Shock tube/laser absorption measurements of the pyrolysis of a bimodal test fuel. Proc Combust Inst 2017;36:281-8. doi:10.1016/j.proci.2016.07.081.

21] Pinkowski N, Ding Y, Johnson SE, Wang Y, Parise T, Davidson DF, et al. A multi-wavelength speciation framework for high-temperature hydrocarbon pyrolysis. J Quant Spectrosc Radiat Transf 2018;225:180-205. doi:10.1016/J.JQSRT.2018.12.038.

22] Wang K, Villano SM, Dean AM. Experimental and kinetic modeling study of butene isomer pyrolysis: Part II. Isobutene. Combust Flame 2017;176:23-37.

doi:10.1016/j.combustflame.2016.07.036.

[23] Grant M, Boyd S. CVX: Matlab software for disciplined convex programming, version 2.0 beta. http://cvxr.com/cvx n.d.

[24] Grant M, Boyd SP. Graph implementations for nonsmooth convex programs, Recent Advances in Learning and Control (a tribute to M. Vidyasagar), V. Blondel, S. Boyd, and H. Kimura, editors, pages 95-110. Springer; 2008. doi:10.1109/ISIC.2014.6967596.

[25] Campbell MF, Haylett DR, Davidson DF, Hanson RK. AEROFROSH: a shock condition calculator for multi-component fuel aerosol-laden flows. Shock Waves 2016;26:429-47. doi:10.1007/s00193-015-0582-3. 
597

598

599

600

601

602

603

604

605

606

607

608

609

610

611

612

613

614

615

616

617

618

619

620

621

622

[26] Gauthier BM, Davidson DF, Hanson RK. Shock tube determination of ignition delay times in full-blend and surrogate fuel mixtures. Combust Flame 2004;139:300-11. doi:10.1016/j.combustflame.2004.08.015.

[27] Alrefae M, Es-Sebbar ET, Farooq A. Absorption cross-section measurements of methane, ethane, ethylene and methanol at high temperatures. J Mol Spectrosc 2014;303:8-14. doi:10.1016/j.jms.2014.06.007.

[28] Wang S, Parise T, Johnson SE, Davidson DF, Hanson RK. A new diagnostic for hydrocarbon fuels using 3.41- $\mu \mathrm{m}$ diode laser absorption. Combust Flame 2017;186:129-39. doi:10.1016/j.combustflame.2017.07.026.

[29] Al Shoaibi A, Dean AM. Kinetic analysis of C4 alkane and alkene pyrolysis: Implications for SOFC operation. J Fuel Cell Sci Technol 2010;7:0410151-8. doi:10.1115/1.4000677.

[30] Zhang Y, Cai J, Zhao L, Yang J, Jin H, Cheng Z, et al. An experimental and kinetic modeling study of three butene isomers pyrolysis at low pressure. Combust Flame 2012;159:905-17.

[31] Pan L, Hu E, Zhang J, Tian Z, Li X, Huang Z. A high pressure shock tube study of 1-butene oxidation and its comparison with n-butane and alkenes. Fuel 2015;157:21-7. doi:10.1016/j.fuel.2015.04.062.

[32] Schenk M, Leon L, Moshammer K, Oßwald P, Zeuch T, Seidel L, et al. Detailed mass spectrometric and modeling study of isomeric butene flames. Combust Flame 2013;160:487-503. doi:10.1016/j.combustflame.2012.10.023.

[33] Manion JA, Awan IA. Evaluated kinetics of terminal and non-terminal addition of hydrogen atoms to 1-alkenes: A shock tube study of H + 1-butene. J Phys Chem A 2015;119:429-41. doi:10.1021/jp5110856.

[34] Trenwith AB. 1 -Butene, 3-Methyl-1-Butene, and of 3:3-Dimethyl-1 -Butene and the Resonance Energy of the Allyl, Methyl Allyl and Dimethyl Allyl Radicals 1970:2805-11.

[35] Bryce BYWA, Kebarle P. The thermal decomposition of 1-butene and 1-butene-4-d3 1958.

[36] Corcoran WH. Pyrolysis of 1-Butene and Cis -2 -Butene 1976. 
623 [37] Es-Sebbar E, Jolly A, Benilan Y, Farooq A. Quantitative mid-infrared spectra of allene and propyne from room to high temperatures. J Mol Spectrosc 2014;305:10-6. doi:10.1016/j.jms.2014.09.004.

[38] Stranic I, Pyun SH, Davidson DF, Hanson RK. Multi-species measurements in 1-butanol pyrolysis behind reflected shock waves. Combust Flame 2012;159:3242-50. doi:10.1016/j.combustflame.2012.06.005.

[39] Stranic I, Pang GA, Hanson RK, Golden DM, Bowman CT. Shock tube measurements of the rate constant for the reaction ethanol + OH. J Phys Chem A 2014;118:822-8. doi:10.1021/jp410853f. doi:10.1016/j.jms.2011.02.003. measurements. Combust Flame 2018;197:423-38. doi:10.1016/j.combustflame.2018.08.006.

41] Sharpe SW, Johnson TJ, Sams RL, Chu PM, Rhoderick GC, Johnson PA. Gas-Phase Databases for Quantitative Infrared Spectroscopy. Appl Spectrosc 2004;58:1452-61.

42] Lattanzi F, Di Lauro C, Vander Auwera J. Toward the understanding of the high resolution infrared spectrum of C2H6 near $3.3 \mu \mathrm{m}$. J Mol Spectrosc 2011;267:71-9.

Es-Sebbar ET, Benilan Y, Farooq A. Temperature-dependent absorption cross-section measurements of 1-butene (1-C4H8) in VUV and IR. J Quant Spectrosc Radiat Transf 2013;115:1-12. doi:10.1016/j.jqsrt.2012.09.014.

44] Klingbeil AE, Jeffries JB, Hanson RK. Temperature-dependent mid-IR absorption spectra of gaseous hydrocarbons. J Quant Spectrosc Radiat Transf 2007;107:407-20. doi:10.1016/j.jqsrt.2007.03.004.

[45] Gordon IE, Rothman LS, Hill C, Kochanov R V., Tan Y, Bernath PF, et al. The HITRAN 2016 molecular spectroscopic database. J Quant Spectrosc Radiat Transf 2017;203:3-69. doi:10.1016/j.jqsrt.2017.06.038.

46] Strand CL, Ding Y, Johnson SE, Hanson RK. Measurement of the mid-infrared absorption 

spectra of ethylene $(\mathrm{C} 2 \mathrm{H} 4)$ and other molecules at high temperatures and pressures. J Quant Spectrosc Radiat Transf 2018;222-223:122-9. doi:10.1016/j.jqsrt.2018.10.030.

651 [47] Johnson SE, Davidson DF, Hanson RK. Shock tube/laser absorption measurements of the pyrolysis of JP-10 fuel. AIAA SciTech Forum 2019:1-7. doi:10.2514/6.2019-0575.

653 [48] Chrystie RSM, Nasir EF, Farooq A. Propene concentration sensing for combustion gases using quantum-cascade laser absorption near $11 \mu \mathrm{m}$. Appl Phys B Lasers Opt 2015;120:317-27.

655 doi:10.1007/s00340-015-6139-4.

656 
Technical Report Documentation Page

\begin{tabular}{|c|c|c|c|c|}
\hline $\begin{array}{l}\text { 1. Report No. } \\
\text { j.fuel.2019.01.154 }\end{array}$ & \multicolumn{2}{|c|}{ 2. Government Accession No. } & \multicolumn{2}{|c|}{ 3. Recipient's Catalog No. } \\
\hline \multirow{2}{*}{\multicolumn{3}{|c|}{$\begin{array}{l}\text { 4. Title and Subtitle } \\
\text { Multi-wavelength speciation of high-temperature 1-butene pyrolysis }\end{array}$}} & \multirow{2}{*}{\multicolumn{2}{|c|}{$\begin{array}{l}\text { 5. Report Date } \\
\text { February } 2019\end{array}$}} \\
\hline & & & & \\
\hline & & & \multicolumn{2}{|c|}{ 6. Performing Organization Code } \\
\hline \multicolumn{3}{|c|}{$\begin{array}{l}\text { 7. Author(s) } \\
\text { Nicolas H. Pinkowski, Séan J. Cassady, David F. Davidson, Ronald K }\end{array}$} & \multicolumn{2}{|c|}{ 8. Performing Organization Report No. } \\
\hline \multirow{2}{*}{\multicolumn{3}{|c|}{$\begin{array}{l}\text { 9. Performing Organization Name and Address } \\
\text { Center of Excellence for: Alternative Jet Fuels and Environment } \\
\text { Stanford University } \\
\text { Department of Mechanical Engineering } \\
\text { Stanford CA } 94305\end{array}$}} & \multicolumn{2}{|c|}{ 10. Work Unit No. (TRAIS) } \\
\hline & & & \multicolumn{2}{|c|}{ 13-C-AFJE-SU-015, 17} \\
\hline \multirow[t]{2}{*}{$\begin{array}{l}\text { 12. Sponsoring Agency Name and } A \\
\text { Federal Aviation Administı } \\
\text { Office of Environment and }\end{array}$} & & & \multicolumn{2}{|c|}{$\begin{array}{l}\text { 13. Type of Report and Period Covered } \\
\text { Journal Article }\end{array}$} \\
\hline & & & \multicolumn{2}{|c|}{\begin{tabular}{|l} 
14. Sponsoring Agency Code \\
\end{tabular}} \\
\hline \multicolumn{5}{|l|}{ 15. Supplementary Notes } \\
\hline \multicolumn{5}{|c|}{$\begin{array}{l}\text { 16. Abstract } \\
\text { Species time-history measurements provide important kinetics targets for the development and validation of detailed reaction } \\
\text { models. Here, a multi-wavelength, multi-species laser absorption strategy is demonstrated that provides high-bandwidth species } \\
\text { time-histories during 1-butene pyrolysis behind reflected shock waves. Measured shock tube absorbance traces at nine wavelengths } \\
\text { were used to resolve nine species mole fractions in the pyrolysis of 5\% 1-butene in argon at } 1300 \mathrm{~K}, 1.8 \text { atm. In addition to existing } \\
\text { sensors for 1-butene, methane, ethylene, 1,3-butadiene, propene, allene, benzene, and cyclopentadiene, a new laser absorption } \\
\text { sensor for ethane at } 3.3519 \text { um was developed by measuring cross-sections of ethane and of expected major interferers. Additional } \\
\text { measurements to complete a square absorption cross-section matrix were also performed that enabled the simultaneous solution of } \\
\text { species mole fractions from absorbance time-histories under appropriate physical system constraints. Measured time-histories of } \\
\text { the nine product species were also compared with existing flow-reactor-based kinetic mechanisms. The demonstrated method has } \\
\text { further application potential in the speciation of larger, more complex fuels. }\end{array}$} \\
\hline \multirow{2}{*}{\multicolumn{2}{|c|}{$\begin{array}{l}\text { 17. Key Words } \\
\text { 1-butene, hydrocarbon pyrolysis, high temperature, } \\
\text { time-resolved, laser absorption spectroscopy, cross-sections, } \\
\text { ethane diagnostic, shock tubes, ASCENT }\end{array}$}} & \multicolumn{3}{|c|}{ 18. Distribution Statement } \\
\hline & & \multicolumn{3}{|c|}{$\begin{array}{l}\text { (C) } 2019 \text { published by Elsevier. This manuscript is made available } \\
\text { under the Elsevier user license } \\
\text { https://www.elsevier.com/open-access/userlicense/1.0/ }\end{array}$} \\
\hline $\begin{array}{l}\text { 19. Security Classif. (of this report) } \\
\text { Unclassified }\end{array}$ & $\begin{array}{l}\text { 20. Security Classif. (o } \\
\text { Unclassified }\end{array}$ & & 21. No. of Pages & 22. Price \\
\hline
\end{tabular}

Form DOT F 1700.7 (8-72) Reproduction of completed page authorized

